\title{
Sexual Reproduction in Pyronema confluens and the Morphology of the Ascocarp.
}

\author{
BY \\ ROBERT A. HARPER, \\ Professor of Botany in the University of Wisconsin.

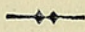 \\ With Plates XIX-XXI.
}

INTRODUCTION.

$7 \mathrm{HE}$ very interesting researches of Stahl (32) on the 1 sexuality of the Collemaceae have received full confirmation from a number of sources, and the doctrine that a type of fertilization similar to that in the red Algae is to be found very generally among the Lichens must be regarded as well established. The nuclear phenomena involved in the fertilization have in no case as yet been worked out, nor is the account of the cell-fusions complete and consistent, still the existence of trichogyne, archicarp and spermogonium, and their interpretation as functional sexual organs can hardly be doubted, in view of the mass of evidence that has been gradually accumulated.

Krabbe's work on Cladonia, Baeomyces, and Sphyridium indicates that these forms may possibly be without sexual organs. Krabbe (20) investigated Cladonia very carefully, and claims that in this genus the ascogenous hyphae are part of the same system of branches from which the paraphyses arise. He notes, that the ascogenous hyphae arise only at one period in the development of a podetium, and that after a certain number have been formed simultaneously, no more new ones arise except by the branching of those already

[Annals of Botany, Vo1. XIV. No. LV. September, I9oo.] 


\section{Harper.-Sexual Reproduction in Pyronema}

present. This is a remarkable condition, assuming that ascogenous hyphae are only modifications of those that form the vegetative thallus. It would be expected that they might bud off at any time from the vegetative hyphae, and in such positions as would be most convenient for the development of asci in the hymenium. Krabbe further describes the ascogenous hyphae in the podetium-stalks as densely staining mycelial branches richly stored with foodmaterials such as glycogen. He also distinguishes them by the fact that their walls stain blue with iodine, as had been earlier observed by Schwendener.

Still, I am of the opinion that it is a question whether these densely filled hyphae are really the ascogenous hyphae. In Ascobolus, Peziza Stevensoniana, Pyronema, and other forms, the ascogenous hyphae are always empty and frequently collapsed in mature fruits, while the branches destined to produce paraphyses, which are to be developed for the continued growth of the hymenium, agree in their general appearance with Krabbe's description of the ascogenous hyphae. I was myself misled for a time by these latedeveloping vegetative branches, their prominence and abundant contents leading naturally to the assumption that they were destined to develop asci. As a matter of fact, however, the asci depend very little on food brought by the ascogenous hyphae, which contain little but nuclei, except perhaps at their very tips. If Krabbe's densely staining hyphae are really vegetative, he would very naturally be led to the conclusion that asci and paraphyses are parts of a common system of mycelial branches, since he would readily find paraphyses arising from these densely stained hyphae, and his preconception that they were the ascogenous hyphae would naturally bias his judgement in determining the difficult question as to their actual connexion with the asci.

This possible mistake of Krabbe's is worth such full consideration, since other students are likely to be led into the error of expecting that the ascus-bearing hyphae will be more conspicuous and more densely filled with protoplasm than 
those which are purely vegetative. The conditions in Pyronema, as will be seen further on, make the true relations of the hyphae in question very clear. A real distinction between ascogenous and vegetative hyphae in all cases so far examined is in the size of the nuclei. Whether this difference will be found in forms yet to be investigated is of course entirely an open question.

As to the actual conditions in Cladonia it is to be further noted that Wainio (41) claims to have found its trichogynes. Wainio and Krabbe agree that the podetium is a fruit and homologous with the apothecia of other Lichens so that the carpogonium should be expected to occur at the origin of an entire podetium rather than beneath each area of hymenial surface. It is in the very young podetia that Wainio claims to have found the trichogyne.

Other authors have claimed for various Lichens that the apothecium develops without carpogonium or trichogyne, but the confirmation of Stahl's work on the Collemaceae will certainly necessitate a reinvestigation of all these forms, on the possibility that the sexual organs have been overlooked, and it is not worth while to discuss them further from the standpoint of the existing observations.

Baur's (1) work on Collema crispum is of especial interest. He confirms Stahl's (32) observations in all respects. Baur's paper is only a preliminary one but he describes and figures carpogonia and trichogynes of the same type as those of Stahl. He finds that carpogonia, whose trichogynes show no spermatia, grow into vegetative hyphae which may become paraphyses if opportunity is given, thus giving what amounts to an experimental proof of the necessity of fertilization by a spermatium if the asci are to be developed. In four cases empty spermatia were found attached to the end of the trichogyne, whose cells showed in these cases the same degenerative changes described by Stahl. The septa between the upper cells of the trichogyne were swollen, and the lower ones were still clearly broken down. Baur finds that the cells of the carpogonium are uninucleate at first, and obtained 


\section{Harper.-Sexual Reproduction in Pyronema}

some evidence that later they become connected by openings through their cross walls. Each cell of the carpogonium becomes a source of ascogenous hyphae, so that such pores in their walls are probably to be associated with some part of the fertilization-process. Baur considers that the first cell of the carpogonium is the egg-cell, and that the rest probably function as auxiliary cells, somewhat as has been described by Oltmanns for certain red Algae.

Darbishire (9) confirms Stahl's and Lindau's discovery of trichogynes in Physcia pulverulenta. He finds a single nucleus in each cell of the carpogonium and trichogyne, which latter rises about thirty $\mu$ above the surface of the thallus. The cells of the carpogonium become connected by broad strands of protoplasm so as almost to form a single, many-nucleated cell. Of most interest, perhaps, is the author's criticism of the interpretation of the trichogyne proposed by Lindau (22). According to this author's latest view the trichogyne has no sexual function, but is a boring organ, 'terebrator hypha,' which serves to break a way upward through the thallus for the apothecium.

Darbishire shows that the trichogyne as a rule does not grow upward to the surface of the thallus in the axis of growth of the future apothecium, but rather to one side or the other. In some cases the trichogyne grows parallel to the surface of the thallus, before it turns to follow the most direct line to the surface. Further, its early disappearance and its thin-walled cells with abundant protoplasmic contents are the opposite of what we should expect of a boring organ intended to open a path to the surface of the thallus. The paraphyses grow upward just like other newly formed hyphae of the kind and need no aid in pushing to the surface. I have myself observed and described for Ascobolus (16) how the mass of paraphyses acts as a wedge to split the spherical fruit-body at its apex and transform it from the cleistocarpous to the discocarpous type of fruit-body.

Lindau's doctrine seems to be merely a guess, at the best, and when thoroughly tested by comparison with the facts, as 
Darbishire has done, it loses all semblance of probability. Lindau (21) in his earlier work has recorded the existence of trichogynes for a considerable series of Lichen-species. His work, taken with Stahl's, Wainio's, and that of the two authors discussed above, makes it certain that organs of this nature are of extremely widespread occurrence among the Lichens. In view of this mass of evidence the negative results of Krabbe, Fünfstück (15) and others, must be regarded as having little weight. It is quite possible that certain genera or families of Lichens may be prevailingly apogamous or parthenogenetic, but that so definite and constant a structure as the ascocarp should be entirely different in its morphological significance in these cases can only be established by positive evidence. It would be most remarkable if such complex structures as the trichogyne, carpogonium, and ascogenous hyphae could be present in Physcia and absent in Cladonia. At present there is no ground for the view that such apparently closely related forms as are the various genera of the ascus-bearing Lichens must be considered as morphologically unlike in such important parts as constitute the ascocarps, until the last detail of the nuclear phenomena in their reproduction has been worked out. So sceptical an attitude of mind is perhaps stimulative of research, but is not well founded, and its existence at present is simply due to the rivalry of opposing schools.

Similar to Lindau's hypothesis regarding the trichogyne, in the lack of evidence for its support, is Van Tieghem's supposition that the trichogyne constitutes an especial respiratory apparatus for the developing perithecium (37, p. II66). This hypothesis has received sufficiently trenchant criticism by De Bary (13, p. 237) and need not be further mentioned here.

For the Lichens in general there remains one difficult point. The spermogonia resemble very closely conidial fructifications, which in many Ascomycetes are plainly asexual reproductive organs. It is hence difficult, in cases in which the germination of these spores has not been satisfactorily tested, and the development of the apothecium has not been worked out, to 
be sure whether the given structures are male cells or vegetative spores. Brefeld and his pupil Möller (4) have endeavoured to overthrow the evidence for sexuality in the Lichens by laborious culture experiments intended to show that cells which have been claimed to be spermatia in many cases will really germinate, and may, under especial conditions of nutrition, produce rudimentary thalli. Möller describes the germination and growth of the supposed spermatia of species of Buellia, Opegrapha, Graphis, Arthonia, and Calicium, and concludes that in every case they are merely conidia, and are capable of reproducing the fungal portion of the Lichen by simple germination and growth. He proposes to call the spermagonia pycnidia and their spores pycnoconidia. Assuming the substantial accuracy of the results as published, though they have not as yet been confirmed by other investigators, it is still quite possible that Möller has pushed too far that conception of sex-cells according to which they must be incapable of further development without conjugation. The inability to develop without conjugation is doubtless an acquired character in the evolution of sexual reproduction from original asexual methods, and it is quite possible in these simple forms, where the spermatia are plainly so similar to known vegetative spores both in their appearance and in the method of their production, that the capacity for independent growth has only been as yet partially lost, so that under conditions of especially rich nutrition, such as Möller's methods furnished, cells which are potential spermatia might return to an original vegetative condition. The weakness of such growth and the failure to achieve it in many cases should have considerable weight, from this standpoint, as evidence of the sexual nature of these spores.

Loeb (23) has shown that such regularly sexual eggs as those of the Echinoderms will still segment regularly and form Pluteus larvae without fertilization simply as a result of changing the percentage of a certain salt $\left(\mathrm{Mg} \mathrm{Cl}_{2}\right)$ in the sea water. These eggs are in nature incapable of further development without fertilization, but a relatively simple change in 
their environment endows them with capacity for independent growth, or, as Loeb puts it, they contain all the elements necessary for development parthenogenetically, but are hindered by some conditions in their environment. In view of such facts as these it cannot be considered as at all surprising that, under the relatively artificial methods of nutrition employed by Brefeld and Möller, the spermatia experimented with should have been stimulated to the degree of vegetative activity they showed. Indeed in view of Loeb's researches, it would seem impossible to further utilize the test of germination without conjugation as a means of positively determining the sexual or nonsexual nature of reproductive cells. The whole literature relating to the morphology and functions of the Lichen-spermogonia prior to 1884 has been thoroughly reviewed in De Bary's handbook (13, p. 240), and I need not discuss it further here.

In view of all these varied observations, both old and new, the existence of trichogynes and carpogonia in the Lichens, essentially similar to those in the red Algae, must be regarded as established. The most essential phenomena involved in the behaviour of the nuclei are still to be worked out, but the sexual significance of the apparatus from which the ascocarp arises can hardly be questioned by any one not already committed to some other view.

In an attempt to discredit the results of my study of Sphaerotheca, Dangeard (8) has investigated the same form and has published a paper with numerous illustrations, quite a number of which might have been copied from my own figures. This paper presents once more the author's theories as to the sexuality of the Ascomycetes, but is also a manifest effort to take account of well-known facts as to the method of development of the ascocarp in the Erysipheae, which he had hitherto seen fit to ignore.

In considering Dangeard's views it is to be noted that there are two problems to be solved in the development of the ascocarp of Sphaerotheca. First, does the ascocarp take its origin from a sexual apparatus, consisting of antheridium and 
oogonium? and second, are these sexual cells functional, or does the egg develop parthenogenetically? According to De Bary's and my own results both of these questions are to be answered affirmatively. As to the first question Dangeard's figures and descriptions are unmistakable. There is a sexual apparatus formed consisting of oogonium and antheridium as the initial step in the development of the ascocarp of Sphaerotheca. As Wager has already pointed out, Dangeard admits this fact, and he repeatedly uses the term antheridium in naming the structure described as such by De Bary. This evidence, coming from an opponent of De Bary's views, must convince the most sceptical that there can be no further doubt as to De Bary's main contention that the ascocarp arises from a sexual apparatus, and is to be interpreted morphologically as homologous in its origin with the sexual reproductive organs of other Fungi and Algae, rather than with their asexual fruit-bodies as maintained by Brefeld, Van Tieghem and others. Dangeard agrees with De Bary that these male and female cells arise from different hyphae, and is inclined to think the hyphae may be from separate mycelia. With the establishment of the existence of an oogonium and egg at the beginning of perithecial development Dangeard's own doctrine that the ascus is an oogonium is left entirely unsupported, unless it is assumed that a sexual apparatus is formed at two stages in the development of the ascocarp, once at its beginning and again when the asci are formed at its maturity. This latter assumption is entirely forced, and without analogy elsewhere among plants or animals. Yet it would seem that Dangeard really supports this view, since he expressly states that the assumption of a fertilization, as he calls it, in the ascus allows perfect liberty of interpretation as to the nature of the archicarps and antheridia, which form the initial cells of the ascocarp, and, as noted above, he continually uses the term antheridium in his description for the cell so named by De Bary. Still it is hard to believe that Dangeard holds seriously to the view that two sets of sexual organs are present in the development 
of the ascocarp. Such a view would certainly represent the antithesis of that which has been recently current, according to which the Ascomycetes are entirely without sexuality.

Dangeard professes to find some support for the view that the ascus is an oogonium in the method of reproduction of Eremascus and Dipodascus. He figures a parthenogenetically produced ascus of Eremascus as an illustration of the nature of the ascus in the Mildews and elsewhere. Whether there would be a fusion of nuclei in such a case is of course unknown. The facts as to the parthenogenetic development of some Crustacean-eggs in which the second polar nucleus fuses with the egg-nucleus might afford support for the view that a nuclear fusion is to be expected here, but, granting the relationship of Eremascus and Dipodascus to the other Ascomycetes, there can be no question that their sexual fructifications correspond to the entire ascogonia and asci of such forms as Sphaerotheca Erysiphe, Pyronema, Eurotium, \&c., and not to a single ascus in one of these fruit-bodies. The gamete-cells of Eremascus and Dipodascus correspond to the initial sexual apparatus of the mildews and Pyronema, and not to the pair or pairs of nuclei in the ascus. This is the interpretation given by Eidam and Lagerheim themselves, and Dangeard brings no evidence against it. Indeed, in his whole paper, Dangeard seems to be seeking to save his original proposition, that the ascus is an oogonium, against the evidence of his own observations on Sphaerotheca. The whole argument seems like an elaborate attempt to escape from the unenviable position of having proposed a theory as to the sexuality of the Ascomycetes, which simply ignored a mass of fully described, easily verifiable facts in the development of so simple a form as Sphaerotheca.

On one point as to the general structure of the ascocarp of Sphaerotheca, Dangeard disagrees with me and holds a position nearer to that of De Bary. He finds that the mature ascogonium consists of only three cells, the middle one of which forms the ascus, while I have found regularly five or six cells in the mature ascogonium, of which the penultimate 


\section{Harper.-Sexual Reproduction in Pyronema}

produces the ascus. This difference, as well as Dangeard's failure to find the conjugation of the antheridial cell and oogonium, is due, I am convinced, to the fundamental weakness of his method of studying the young fruits. I have repeatedly proved in my own experience, as have many others, that it is impossible to get clear views of the fruits, resting as they regularly do on and in an intricate web of vegetative hyphae, except by slicing this mass into thin and transparent microtome-sections.

To the second general question noted above, as to whether the sexual apparatus described is functional, Dangeard replies in the negative. He fails to find any evidence of a conjugating pore between the antheridium and oogonium. In some cases the antheridial cell and nucleus degenerate early while the oogonium is still uninucleate, though in others the antheridial nucleus is still to be found in the antheridium after two nuclei are present in the ascogonium; Dangeard claims to have examined so much material that this purely negative result must be accepted as a final and indisputable proof that the conjugation which he fails to find does not exist. In spite of this certainty, however, I am quite convinced that a more protracted and painstaking search and better methods would have brought to light the stages in development which Dangeard failed to find. Any one who has worked on fertilization-phenomena, either in plants or animals, knows how extremely difficult it is to bring together a complete series of the stages involved, and that negative evidence in such cases has very little weight. De Bary attacked the problem with essentially the same methods of preparation as were used by Dangeard, and failed at exactly the point at which Dangeard has failed, that is in discovering the conjugation-pore between the male and female cells. Dangeard's investigation leaves the problem where De Bary left it.

Wager (40) has pointed out the possibility that Dangeard had a parthenogenetic form of Sphaerotheca before him, but I am not inclined to accept this view, and am still convinced that he has failed to find the fertilization-stages because 
of his reliance upon antiquated methods of preparation. Dangeard assumes that the nuclear fusions in the ascus are much more easy to find than those in the oogonium. This is true for the larger cup-fungi where scores of asci can be mounted in a single preparation, since the larger number increases proportionally the chances of finding the particular stage in question, but it is not true in Sphaerotheca, where each ascocarp produces only a single ascus. I have found it just as easy to discover the conjugation-pore and true sexual fusion of the male and female nuclei in Sphaerotheca as to find sections showing the nuclear fusion in the ascus.

Dangeard evidently considers the fact that the male nucleus is smaller than the egg-nucleus prior to the conjugation, as evidence that the former is degenerating. He also regards it as an inconsistency in my figures that the male nucleus at the time of fusion with the egg-nucleus has become as large as the latter. It should not, however, be necessary to point out to a student of fertilization-phenomena that it is an extremely common condition in both plants and animals to find not only the nucleus, but the entire male cell at certain stages much reduced in volume, and that it is not at all uncommon to find that the sperm-nucleus has increased in volume at the time when it unites with the egg-nucleus.

Miss Nichols (25) has also investigated the development of the ascocarps in a number of Pyrenomycetes. If one judges by the impression produced on her reviewers, Miss Nichols's results, so far as the question of sexuality in the forms she investigated is concerned, must be regarded as somewhat ambiguous. Sydow considers that Miss Nichols's observations revealed not a trace of sexuality in the forms investigated (!), while Wager (40, p. $\left.5^{84}\right)$ states that her work distinctly supports the view that sexuality is present.

Miss Nichols's account of the development of the ascocarp of Teichospora and Teichosporella by the division of a single hyphal cell to form an oval parenchymatous mass is certainly very interesting. As I understand her description 


\section{Harper.-Sexual Reproduction in Pyronema}

it agrees very exactly with the method of development described by Bauke (2) for the ascocarp and pycnidium of Pleospora, though Miss Nichols does not refer to this author. De Bary had already expressed the view regarding this method of ascocarp-formation, that it is quite fundamentally different from that in other Ascomycetes and is to be interpreted as a case of apogamy. We shall need to know more than Miss Nichols describes of the nuclear phenomena in these initial cells, and of the development of the ascogenous cells before an interpretation of this method of ascocarp-formation can be attempted. The account given of the sexual organs in Ceratostoma and Hypocopra is not widely different from that of Woronin for Sordaria, as Miss Nichols points out.

Because of the large size and conspicuous occurrence of the sexual apparatus above the substratum, Pyronema was one of the first Ascomycetes to be thoroughly investigated. $\mathrm{R}$. and C. Tulasne (35) observed in $\mathrm{I} 860$ the presence of large globular vesicles on the mycelium, which they recognized as the first indication of approaching fruit-formation. They called these vesicles macrocysts, but failed to discover their sexual character or that they were of two kinds.

De Bary (11, p. II) in I 863 published a further account of the Fungus in which he points out that these vesicular cells are in pairs consisting of a thicker flask-shaped oogonium and a club-shaped antheridium. He describes the groups or rosettes consisting of several of these paired bodies as arising from one or a small number of mycelial twigs. $\mathrm{He}$ also observed a gradual disappearance of the protoplasm from the pairs as they become enclosed in the enveloping hyphae of the hypothecium. He also finally settles the point that there is no fertilization of the asci by the paraphyses, and throws doubt on the existence of the conidial fructification earlier described by Tulasne. He was unable, however, to find an actual fusion between the peculiar paired bodies which he describes.

In this respect he left the matter exactly in the condition 
in which he left our knowledge of Sphaerotheca, having in each case described the sexual apparatus without being able to prove a fusion of the sexual cells. At that time, however, it was supposed that mere contact of the male and female cells might be sufficient for fertilization. De Bary was naturally unable to determine the exact function of the intermediate cell, or trichogyne, as he later called it. $\mathrm{He}$ describes the paired bodies as in intimate contact throughout their whole length, a statement which is corrected by Tulasne (36, p. 218).

In 1866 (36) the Tulasne brothers published further results of their investigations on Pyronema, in which they describe the fusion of the paracyst (antheridium) with the tube at the apex of the macrocyst (oogonium). They were able to observe the actual union of the protoplasm of the connecting tube and paracyst-cells through a rounded pore formed at their point of contact. This pore they described as having a thickened border (bourrelet). The connecting tube is cut off from the oogonium before its fusion with the paracyst. They also recognized the difficulty of determining which of the two cells is the active organ in effecting the conjugation. In some cases the connecting tube seemed to extend over more than its proportion of the distance necessary to bring the two together. Again the paracyst seemed to anticipate this action of the connecting tube. They further observed, what is quite true from a surface view of the facts, that if the protoplasmic contents of the conjugating cells do influence each other reciprocally, this influence does not produce any appreciable change in their appearance. The interpretation of the fusion they leave uncertain, but point out that the conjugated cells ultimately wither and become empty (especially the macrocysts), while the filaments grow up about them which are to form the ascocarps (theques) of the Fungus. They observed no development of branches from the macrocyst, and apparently supposed that the asci arose from the filaments that build the envelope around it. They give a long series of beautiful figures of the conjugating 


\section{Harper.-Sexual Reproduction in Pyronema}

groups in all stages of their development, which leave nothing to be desired as to accuracy and detail so far as the surface views of the structures are concerned. In the Carpologia the Tulasnes described the formation of asexual spores of Pyronema. In the paper under consideration, they correct this error and assign the earlier described conidial spores to Peziza melanoloma which they found frequently associated with Pyronema.

Kihlmann in 1883 (19) was the first to discover the development of ascogenous hyphae from the archicarp (macrocyst) of Pyronema, and thus bring the sexual process here into line with what Janczewski (187I) had already described for Ascobolus. Kihlmann made a very careful study of the form, and the account in De Bary's handbook (13) is based on his work. He concludes, although without very positive evidence, that the macrocysts and paracysts of a group arise from separate hyphae. He never observed a macrocyst and paracyst arising from a single hypha. He describes them as arising simultaneously in from six to sixteen pairs in each group or rosette. The paracysts are a few $\mu$ longer than the macrocysts and about one half as thick. Sometimes two conjugating tubes connect with one paracyst. One case was observed in which the paracyst was branched, though remaining one-celled, and each branch was connected with a macrocyst by conjugating tubes. The conjugating pore between the paracyst and conjugating tube is $3^{-4} \mu$ in diameter, and is bounded by strong sutures. He was able, by pressure on the paracyst, to cause a flow of protoplasm through this pore from the paracyst to the conjugating tube. When the pressure is relieved a return flow is set up.

Kihlmann also finds that the cross-wall at the base of the conjugating tube is always formed before the latter fuses with the paracyst, so that a direct mixing of the protoplasmic contents of the paracyst with that of the macrocyst is impossible. He thinks, however, that a diffusion of dissolved substances may take place through this basal wall of the conjugating tube, and that thus fertilization may be effected. 
In this connexion he makes the interesting observation that a button-like granule is present on the middle of this basal wall of the conjugating tube in its younger stages on the side toward the macrocyst, and that this granule disappears in older stages. He notes also that it stains yellow with iodine and swells from two to three times its original volume when treated with caustic potash solution.

After the formation of the conjugation-tube the macrocyst swells to two or three times its original volume. Later, branches arise from its surface as papillae, and grow out, piercing between the vegetative enveloping hyphae which are already present. These branches at their point of origin are much thicker than the paraphyses. They are very crooked and soon become septate.

Kihlmann believed that the asci were developed from the ultimate ramifications of these branches, but he was not able to trace the connexion directly from macrocyst to ascus. As these ascogenous branches develop, the macrocyst becomes emptied and vesicular and is not recognizable in the old fruit. At the time when the ascogenous hyphae begin their development, the antheridium and conjugation-tube are still full of protoplasm, which is sometimes very vacuolar. Kihlmann suggests the possibility that the basal wall of the conjugationtube may become swollen, as do the cross-walls of the trichogyne in Collema, and that the disappearance of the granule mentioned above may be associated with this change.

As to the homologies of the parts concerned, Kihlmann agrees with De Bary that the macrocyst is an ascogonium, the paracyst an antheridium, and the branches of the macrocyst are ascogenous hyphae. The whole structure is similar to that in Collema as described by Stahl, with the difference that in Pyronema the trichogyne is reduced to a single cell, and the ascogonium is also unicellular. The development of several ascogonia to one ascus-fruit is also found in Physma and Collema. He also considers that the development of the male element as an antheridial branch in Pyronema, and as 


\section{Harper.-Sexual Reproduction in Pyronema}

a spermogonium in Collema is due to the development of dioecism in the latter.

Kihlmann concludes, however, that the actual fertilization of Pyronema is still an hypothesis. The homology of the reproductive organs is unquestioned, but the possibility that they are not functional still remains, since parthenogenesis and apogamy are widely distributed phenomena. The nature of the sexual process was much better understood when Kihlmann published his work in 1885 , than it was when Tulasne and De Bary did their work. Still in spite of the progress that had been made, Kihlmann remarks that he considers it a question whether nuclei are present in the sexual cells of Pyronema, and further, whether their behaviour, if present, would show phenomena of decisive worth for settling the question of fertilization.

\section{ObServations on Pyronema。}

The sexual reproductive apparatus in Pyronema is the largest and most conspicuous which has yet been discovered among the Ascomycetes. In it we have a case analogous to that of Sporodinia among the Zygomycetes, in which the zygospores, contrary to the habit of the group, are produced on an aerial mycelium instead of beneath the surface of the substratum. The young ascus-fruits of Pyronema are visible with a good magnifier, and their distribution and approximate stage of development can thus be determined with considerable certainty.

I found the form used, which seems to be $P$. confluens, abundant in woods on burned places, especially in half-charred masses of leaves, though it also occurs among damp welldecayed leaves where there has been no fire. When conditions are favourable it is extremely common, and can be obtained in unlimited quantities in all stages of growth. The development of the mature fruits from the time of the appearance of the sexual apparatus only requires a few days. The development of the sexual apparatus itself up to the stage when fertilization occurs requires not more than twenty-four 
hours. The fruits are densely packed in small tufts, and are a delicate pinkish or salmon colour when growing among leaves. The mycelium and sexual organs are glistening white, and resemble a delicate frost-like tracery on the blackish substratum. The best material is always found under and among the leaves, so as to be at least partially protected from the brightest light in the cases I have observed, though it is described as growing directly on the ground on burned places in Europe. My material was collected in May and June of 1898 at Lake Forest, and I was able to obtain unlimited quantities of it at that time, sufficient for experimenting with all varieties of fixing-fluids, \&c.

As just noted, the material for my investigations was found growing on charred or decayed leaves or leaf mould. Bits of this substratum a few $\mathrm{mm}$. in diameter and richly covered with fruiting bodies, young or old as might be desired, were fixed in toto, embedded in paraffin and sectioned for the most part in a plane vertical to the surface of the substratum as it lay when collected. In this way the sexual apparatus was fixed without distortion, as would hardly have been possible had the attempt been made to handle the rosettes of oogonia and antheridia separately. The growth of the mycelium is peripheral, from a centre outward, and the bits of the substratum usually contained fruits of varying ages, the youngest lying near the border of a mycelial growth with progressively older stages toward the centre. The development is, however, so rapid that it is not possible to find the fully mature as well as the youngest stages on any single mycelium. The oldest fruits found on mycelia, at whose edges the rosettes were first appearing, showed only a few partly ripened asci, and conversely those mycelia which showed fully mature pink apothecia at their centres rarely bore fruits as young as the fertilization-stages at their margins. By noting such points as this one is enabled to be sure of obtaining an abundance of material at all stages of development. The substratum on which I have found the Pyronema most abundant, makes it especially favourable for sectioning, 


\section{Harper.-Sexual Reproduction in Pyronema}

the leaves or leaf mould offering little or no resistance to the microtome-knife. More trouble is sometimes occasioned by diatoms, which were found extremely abundant in the substratum in some cases, and indicate the degree of moisture favoured by the Fungus. Blue-green Algae and some Conferva-like filamentous species were also present in many cases. Pyronema, as I have found it, is extremely susceptible to drought, a short exposure in the laboratory causing it to wilt and die. These points as to its occurrence are of interest in comparison with Kihlmann's experience. He seems to have found the Fungus abundant in clefts on stones and to have secured successive crops of young fruits by wetting the stones every three to four days.

For fixing my material I used Flemming's solutions, both the stronger and weaker, and also of a strength about half that of the weaker formula. Hermann's and Merkel's solutions were also tried. Of the sublimate acetic solutions both Kaiser's and Wilson's were tried. Merkel's solution was found far superior to all the others as a fixing-agent for the younger stages in the development of the fruits, up to the time of ascus-formation. Solutions containing osmic acid such as Flemming's solutions in any strength seem to reduce the protoplasm, of the oogonium especially, to a dense undifferentiated mass in which even the differential staining of the nuclei was a matter of great difficulty. This action of the solutions containing osmic acid seems due to the presence in the protoplasm of the reproductive cells of certain reserve food-materials whose nature I have not attempted as yet to more fully determine. As a result of their presence young material fixed in Flemming's solution was practically useless. Merkel's solution, however, gave preparations of a clearness which left little to be desired. The sublimate solutions gave well-fixed and unshrunken sections which, however, seemed not well suited to differential staining with the anilin dyes. With iron-haematoxylin this material gave very good figures, but the plain black or blue and white is far less useful than the series of varied shades which can be obtained with such 
combinations as the safranin-gentian violet-orange, or acid fuchsine and iodine green, when used on material fixed in Merkel's solution. The earliest stages figured are from preparations stained with acid fuchsine and iodine green. The fertilization-stages were mostly drawn from preparations treated with Flemming's triple stain. For the nuclear phenomena in the ascus the Flemming fixing-solution, weaker formula, and the triple stain were used.

I have mentioned the slight differences in the habit of the Fungus studied from what is described for Pyronema confuens in Europe. I have no doubt, however, that our plant is the same species. The general specific characters agree very well, and the reproductive organs in the fresh preparations I have studied might have served for Tulasne's drawings.

The mycelium is made up of cells of varying length which are regularly multinucleate, containing from six to twelve or more nuclei (Pl.XIX, Fig. 2). They are filled rather evenly with protoplasm of a loose spongy structure, there being as a rule no conspicuous large central vacuole. As a whole the mycelium is extremely sparse and loose, never making densely felted layers in my experience. The sexual organs are, however, very abundant, especially at the centre of the mycelium, so that when the ascus-fruits are mature they are frequently densely packed together, forming continuous irregularly circular turfs. Toward the margin of the mycelium the reproductive organs are progressively more sparse, and the resulting fruits stand isolated. The whole arrangement indicates peripheral growth of a mycelium from a central point about which most of the fruits are developed. Such a condition would naturally result if each such radially growing mycelium were the product of the growth of a single spore. Whether this is the true interpretation in every case is doubtful. It is quite possible that this arrangement of the mycelia indicates the relative distribution of moisture, food material, \&c., favourable for the life of the Fungus. The centre of most vigorous growth would then indicate a point at which conditions were especially favourable. A filament of a neighbouring mycelium 


\section{Harper.-Sexual Reproduction in Pyronema}

reaching such a point would, by its vigorous branching, produce a centre of growth and result in a radially arranged mycelium such as I have described. The Fungus certainly spreads by means of loose, cobwebby hyphae over considerably greater areas than are ultimately covered by the apothecia. These scattered hyphae are hardly to be described as definite stolons such as are found in Rhizopus, and yet their general function is much the same.

I have never found any traces of asexual reproduction by conidia or otherwise. Sexual reproduction is so prolific apparently, and the ascus-fruits are produced in so short a time, that asexual reproduction has been dispensed with. I have not tried germinating the spores in nutrient media, and it is quite possible if they could be made to grow in this way that some type of vegetation fragmentation might appear, but it is quite certain that such reproduction does not occur, or at least does not play any prominent rôle in the life history of the Fungus in nature. Pyronema has developed the opposite habit to that found in Penicillium, for example, where the asexual conidia are the predominant reproductive bodies, ascocarps being formed rarely or perhaps never in nature. What has led to such different lines of development in the two forms is as yet an unsolved problem. Doubtless the explanation of the predominance of the Penicillium and the comparative rarity of Pyronema is involved to some degree at least in this difference in their reproductive habit.

Vertical median sections through a mycelial growth such as I have described show ascocarps in various stages of development, the older near the centre, the younger toward the periphery. The first indication of sexual reproduction, as it has so many times been described, consists in the formation of thickened hyphal branches which tend to stand vertical to the substratum. Thin microtome sections are not favourable for the investigation of the question as to whether these knots of hyphae arise from one or more than one parent branch. The results of a study of the question on living material by the different authors have been already referred 
to. The point is not a vital one in settling the question of the existence of sexuality in the form, since differentiation of sex has been shown everywhere in plants and animals to occur at earlier or later stages in the life history of the individual as a result of the influence of factors which are as yet little understood.

A section through these knots of hyphae shows that they are composed of multinucleated cells, with denser contents, but not otherwise different from ordinary vegetative mycelial cells. There is no one-nucleated stage in any of these cells. They are formed by growth and division of multinucleated hyphal cells in general as the cells of Cladophora are. The apical cells of these short branches soon show more rapid growth than those immediately below them, and become swollen. They are filled with spherical or oval vacuoles at this stage so that their contents have a foamy appearance as if growth had gone on so rapidly that sufficient protoplasm to fill the swelling cell could not be provided at once. At a very early stage it is possible to differentiate two types of these apical cells, one more spherical-the young macrocyst of Tulasne, which is the oogonium - the other more oblong or club-shaped-Tulasne's paracyst, which is the antheridium.

Very soon a slight elevation or papilla appears on the apex of the oogonium, and this is the beginning of the young conjugating tube or trichogyne (Fig. 3). Both antheridium and oogonium are multinucleated from the start, and the number of nuclei increases by division as the cells grow in size. The nuclear multiplication, however, is out of proportion to the vegetative growth, so that when the sexual cells are mature they contain relatively to their size many more nuclei than do the ordinary vegetative mycelial cells. A broad stalk-cell is usually cut off from the base of the oogonium relatively late in its development, after it has attained its full size or nearly that (Fig. 5). A number of stalk-cells can also as a rule be distinguished at the base of the antheridium (Figs. 6 and 19). The papilla-like beginning of the conjugating tube on the oogonium rapidly elongates with the growth of 


\section{Harper.-Sexual Reproduction in Pyronema}

the latter (Fig. 4). The club-shaped antheridium is slightly curved over the oogonium, and the conjugating tube grows upward on the broad rounded end of the former. The apex of the antheridium reaches to or a little past and to one side of a line through the long axis of the oogonium and its stalk (Figs. I and I4). The conjugating tube lies in this same axis at the start, but coming in contact with the antheridium it applies itself closely to its surface and thus becomes curved and sometimes even hook-shaped to conform to the surface of the antheridium.

It may grow directly up over the apex of the antheridial cell and then bend slightly to the right or left at its tip. More commonly the antheridium extending beyond the vertex of the oogonium, the conjugating tube grows up on one or the other of its flanks, and then bends forward and applies its tip to the former a little above its vertex. Frequently the end of the antheridium bends towards the conjugating tube as if to encircle it so that the tube comes to lie partly enclosed by the antheridium. Sections in such cases make it appear as if the tube cut through the antheridium (Pl. XX, Fig. I4). Antheridium and tube are growing at the same time, and their attraction for each other is apparently mutual. Frequently, the antheridium presses against the tube so that a groove is formed in its side in which the tube lies. The upper margin of this groove may then be developed into a swollen lip. All of these conditions and others have been beautifully figured by the brothers Tulasne (36), and I have not thought it necessary to reproduce them further than $I$ have done in Fig. I which is a surface view of a group mounted in glycerine.

The contents of the conjugating tube are at first in direct connexion with the oogonium through its base (Fig. 4). It is multinucleated at this stage and its nuclei are not different from those in the oogonium. Early, however, and long before its tip becomes fused with the antheridium, a cross-wall is formed at the base of the tube, cutting it off from the oogonium. This wall is formed before the sexual cells or 
the tube have reached their mature size. During subsequent growth it is interesting to note that the nuclei of the tube do not increase in size as do those in the antheridium and oogonium, so that the diameter of these nuclei of the tube remains regularly less than that of the nuclei of the sexual cells themselves. This condition continues until the nuclei of the tube are about to disintegrate, as will be described below, when they swell up without increase of their contents until they may equal in size the nuclei of the sex-cells, but are very transparent. Whether nuclear divisions occur in the tube after it is cut off I am not certain.

Kihlmann has described a button-like granule on the basal wall of the conjugating tube next the oogonium. I have found in some cases a similar granule or pair of granules (Figs. 12 and 18 ). They are doubtless connected with some system of pores by which materials pass from one cell to the other. I have found in Ascobolus and other Pezizaceae, as well as Pyronema, a row of granules on each side of the septa of vegetative hyphae in the hypothecium. I have observed them also in the mycelial cells of Pyronema, and very strongly developed in the swollen storage-cells of the hypothecium (Figs. 2 and 24).

The tip of the conjugating tube is blunt and rounded at first (Fig. 4), but when mature is always narrowed into a beak or snout-like projection at its apex. This beak is about one half the diameter of the body of the tube and serves as the special organ for fusion with the antheridium. When conjugation is complete the tube at the point where it narrows into this snout is always pressed firmly against the antheridium. The snout on the other hand at first bends slightly up and away from the surface of the antheridium, and then turns sharply down at its tip, which thus strikes the wall of the antheridium again almost at a right angle (Figs. 6, 12, 17, and 2I). The tip of the tube is pressed closely against the antheridium wall and the conjugation-pore is then formed as will be described below. This bend in the beak-like end of the conjugation-tube is always well shown when the section 


\section{Harper.-Sexual Reproduction in Pyronema}

lies in the long axis of the beak, and it gives very much the appearance of the piercing of the antheridial wall by the end of the beak, but taking the appearance and arrangements of the parts as a whole it is easy to see how Tulasne was led to the conclusion, that it is impossible to say whether the antheridium or the conjugation-tube is the more active in accomplishing the fusion. This mutual approach of the two cells is perhaps most conspicuous in surface views of the sexual organs such as Tulasne studied (see Fig. I). This mutual attraction and bending of both cells might be expected between equal gametes. In the bulk of Fungi which show antheridial branches it is the latter which are the active structures, and in their growth apply themselves closely to the surface of the oogonium, but here the female cell has also developed an organ - the conjugating tube-which is at least equally active with the antheridium in effecting the union.

The mature sexual apparatus shows nothing further than has been already mentioned in the development of its parts. Its structure may be summarized as follows :

The oogonium is a spherical or flask-shaped cell filled with dense protoplasm and many nuclei which are very much larger than those of the ordinary vegetative cells. Its stalk consists of two or three broad disk-shaped cells of which the basal one is a part of the mass of thickened swollen cells forming the base of the rosette. The apex of the oogonium is continued into the narrow conjugating tube which curves upward to unite with the end of the antheridium. The antheridium is a curved club-shaped cell thickest near its upper end and tapering gradually to its base where it is continued into a stalk of one or more cells. The basal wall of the antheridium is as a rule somewhat higher up than that of the oogonium. It follows a somewhat oblique path upward, conforming rather closely to the surface of the oogonium, and its apex is even with, or reaches somewhat past, that of the latter. The mutual relation of these sexual cells in a typical case will be best understood from Fig. I. 
The nuclei of the antheridium are of about the same size as those of the oogonium. The protoplasm of the antheridium stains much less densely than that of the oogonium, owing perhaps to the absence of accumulated reserve materials. As a result the nuclei are more sharply differentiated in the antheridium, since they stain quite as intensely as those in the oogonium. These sexual nuclei are relatively large and very clearly defined in their structure. They contain a very small spherical nucleolus which appears bright red when the triple stain is used. The chromatin forms a conspicuous net of granules and fibres staining blue or violet with the same triple stain. For those who are still sceptical as to nuclear structures in the Fungi it should be said that these sexual nuclei of Pyronema are quite as conspicuous and quite as available for study by their staining qualities as are the nuclei of many of the higher plants. Even prior to the fusion of the antheridium and conjugating tube, short branchlets are to be found budding out from the stalk-cells of the oogonium and the neighbouring vegetative cells, and these later grow upwards to form the hypothecium and paraphyses. Whether such branches arise also from the stalk cells of the antheridium is uncertain. They certainly are not present at this early stage, and later after the fertilization has been accomplished it is difficult to make out with certainty the origin of all the hyphae which are combined to form the young fruit-body.

If we turn to the process of conjugation and fertilization in the sexual apparatus just described, it is apparent that to permit the union of the male and female cells in addition to the fusion already mentioned as occurring between the tips of the antheridium and conjugating tube, the breaking down of a second wall at the base of the conjugating tube between it and the oogonium is necessary. The first of these two fusions was discovered by the Tulasne brothers (36) and studied fully by them and by Kihlmann (19). These investigators, however, were unable to observe the breaking down of the basal wall of the conjugating tube, and their 


\section{Harper.-Sexual Reproduction in Pyronema}

demonstration of a true fertilization, involving the fusion of male and female cells, was hence incomplete. Kihlmann's statement, that true fertilization in Pyronema was still only an hypothesis, was in a sense justified from the facts as he was able to work them out. For De Bary who, at the time he worked on Pyronema, believed in the possible transmission of a fertilizing influence through a cell wall and without fusion, the case was easier. As a matter of fact, as is shown in Figs. I 5 and $5_{5} a$, the second fusion between the base of the conjugating tube and the oogonium does occur, and thus, as will be seen from the following description, all doubt as to the existence of sexuality in Pyronema disappears.

If we examine now in detail the changes in the sexual apparatus after it has reached maturity; which lead up to fertilization, we shall find first of all, that an area of protoplasm in the antheridium, in the region where the tip of the conjugating tube is pressed against its wall, is differentiated as a very finely granular disk, and that the nuclei have withdrawn from this region (Figs. 7-I2). This finely granular area, although located in the antheridium, is quite similar in shape and consistency to the so-called mouth-piece or receptive spot seen on the oospheres of Oedogonium, Vaucheria, and other Algae. It is an irregularly lens-shaped mass of hyaline protoplasm aggregated at the point where the first fusion-pore is to be formed. If we examine the beak-like prolongation of the conjugating tube we find that it also contains no nuclei, and its protoplasm is also denser and more finely granular than that further back in the tube (Figs. 6 and 9-12). The differentiation of the protoplasm here is not so conspicuous but is quite as characteristic as in the area opposite it in the antheridium, and it doubtless indicates the differentiation of a special receptive spot equivalent to the hyaline mouthpiece in the Algae referred to above. It is less conspicuous only because it is enclosed in the narrowed beak so that it cannot take on the characteristic lens shape. These areas are evidently especially differentiated as a preparation for the process of fusion and may be regarded as a real 
equivalent of the receptive spot in the oospheres mentioned. That such an area occurs in the male cell as well as in the female cell is a further indication, in addition to the facts noted above, that the antheridium in this case is not alone the active element, a mutual reaction being rather induced between both antheridium and conjugating tube. I have not found this receptive spot in the antheridium until after the conjugating tube was in contact with it at its apex. The corresponding area in the conjugating tube is developed as the beak is formed. In their late appearance these structures differ from the receptive spot in the oospheres mentioned, which by some authors have been regarded as centres for the diffusion of substances which serve as a chemotactic stimulus to the male cell to attract it to the egg.

The walls of the antheridium and conjugation-tube, at the point where the beak of the conjugation-tube is closely pressed against the antheridium, break down, and a pore is formed leading from the tube to the antheridium. The process of solution of the wall seems to be a rather gradual one and to consist in the softening and dissolving of the wall-material which swells and seems to spread gradually out into the protoplasm of the beak. Sections at this stage show the hitherto sharply defined walls replaced by a spongy mass, which stains deeply with safranin and seems to be diffusing upward into the beak as fine fibres or ragged shreds (Figs. $8,9)$; on the side next the antheridium there is no indication of such diffusion of the swollen wall-material into the fine granular plasm of the male receptive spot. This perhaps indicates that the solvent action on the wall is mainly exerted from the interior of the conjugation-tube.

Ultimately a circular disk of the walls is entirely dissolved away, leaving the roundish pore through which the protoplasm of the two cells becomes perfectly continuous. Irregular deeply staining bits of material remain for some time in the neighbourhood of the pore representing the swollen but not completely dissolved fragments of the broken-down wall (Fig. IO). Tulasne and Kihlmann have both noted the 


\section{Harper.-Sexual Reproduction in Pyronema}

thickening of the walls around this pore. This thickening is quite conspicuous in sections and seems to be for the most part on the wall of the tube rather than on that of the antheridium. Figs. 9-1 3 show it extending back over a portion of the underwall of the beak. As a result of this thickening an extremely strong suture is formed between the antheridium and conjugating tube, so that they can be bent and turned up on each other as Kihlmann's figures show without being pulled apart. Without doubt this extra reinforcement of the walls at this point is necessary to withstand the strain which comes with the passage of the nuclei from the antheridium into the conjugating tube. The flow of nuclei from the relatively wide cavity of the antheridium through the narrow pore and beak of the conjugating tube must produce considerable strain on the walls of the latter, and the thick irregular ring-shaped thickening provides against the possibility of a rupture. While the pore has been forming, the centre of the lens-shaped receptive spot of the antheridium has become spongy and vacuolar (Figs. II-I2), and its especially fine granular structure gradually disappears.

During the process of fusion just described the contents of the conjugation-tube have been undergoing a striking change. The protoplasm of the tube has finer meshes and stains less deeply than that of the oogonium. At its first maturity, before the pore is formed, its nuclei are much smaller than those in the oogonium. These nuclei now undergo degenerative changes of quite a characteristic type. Their chromatin content seems to be reduced and is distributed for the most part on the nuclear membrane. For a time the minute redstained nucleoli become more conspicuous. The nuclei then swell and become extremely transparent (Fig. 6). They may also tend to flow together in groups in the axis of the tube. Finally they collapse or break down into dense strands or shreds which are frequently connected so as to form a coarse, much broken network in the protoplasm (Figs. 8-I3). This network stains strongly with safranin and seems quite evenly distributed through the tube with the exception of the beak. 
The individuality of the nuclei is entirely lost in this disintegration, and it is quite impossible to determine at this stage just how many or how large shreds have come from a single nucleus. The partial union of the shreds into a network seems to have resulted from the aggregation of the nuclei in groups just before they lose their spherical shape and disintegrate. Having broken down they are apparently once more rather evenly distributed in the cytoplasm, but the fibrous shreds into which they have disintegrated remain more or less connected. This disintegration of the tubenuclei may be complete at the time the pore is formed or it may be delayed somewhat, so that cases are found where the pore has been formed while the tube-nuclei are still intact (Fig. 7).

When the nuclei of the tube are completely disorganized, a migration of the nuclei from the antheridium through the pore begins. Figure 13 shows a case in which three of the antheridial nuclei have entered the beak of the tube, and the tube-nuclei are broken down into the irregular network described. With the inflow of these antheridial nuclei the entire protoplasmic contents of the tube become still further disorganized. This may go so far at once that the fragments of the tube-nuclei disappear entirely, apparently being assimilated by the inflowing antheridial nuclei and cytoplasm (Fig. I4); or the protoplasm of the tube may become aggregated into a densely staining mass embedded in which the remnants of the nuclei appear as very densely stained lumps and granules. This mass may persist after the entire process of fertilization is complete (Figs. I 5 and $\mathrm{I} 7 a$ ) in some cases, and it may remain in the tube or it may be carried through into the oogonium after the basal wall of the tube has been broken down. In very many cases it can still be recognized in the tube after the fruit-body is practically mature, and the oogonium and antheridium appear as mere empty shells. The antheridial nuclei continue to pass through the pore into the tube until the latter is quite densely filled (Fig. 14) and sometimes a trifle swollen. 


\section{Harper.-Sexual Reproduction in Pyronema}

Meanwhile conspicuous changes have been taking place in the oogonium. When mature the oogonium was filled with very densely staining protoplasm, and its nuclei were evenly distributed through its whole interior (Figs. 6, 7, and 10), but with the migration of the antheridial nuclei into the conjugation-tube, the nuclei of the oogonium begin to migrate toward its centre (Fig. I4) where they become collected in the most typical cases in a very dense hollow sphere, the diameter of this sphere being about half that of the entire oogonium. Very frequently, however, instead of forming a sphere, the aggregation of nuclei may take the form of an irregular crescent either in the upper or lower half of the oogonium. In less frequent cases several masses of nuclei are formed instead of a single one.

The cytoplasm of the oogonium around this mass of nuclei has entirely changed its appearance. Instead of being charged with strongly staining substances it has become extremely tenuous and loosely spongy in its texture (Figs. I4, I5), so that the nuclei stand out much more sharply differentiated than before. The nuclei in this central mass are embedded in a cytoplasm which is essentially similar to that in the periphery of the oogonium. There has been an actual disappearance from the protoplasm of a considerable amount of densely staining substance at this stage, but its fate is by no means certain. The oogonium has also increased somewhat in size and its wall has become somewhat thicker; but whether these ordinary phenomena of growth are sufficient to account for the change in the density of the protoplasm must be left undetermined. After the oogonial nuclei have become aggregated in the centre of the oogonium the basal wall of the conjugation-tube breaks down (Figs. $15,15 \alpha$ ), and the antheridial nuclei are admitted to the oogonium where they pass at once to the central mass of egg-nuclei and become mingled with them. Fig. I4 shows that there is no special differentiation of the protoplasm on either side of the basal wall of the conjugation-tube either before or at the time of its disintegration. There is no formation 
of dense disks of fine granular cytoplasm such as were observed in connexion with the fusion of the tube with the antheridium. The receptive spot seems to be associated here as in the Alga egg with the bringing together and fusion of two cells which have not been in contact, and to be entirely unnecessary where the mere breaking down of the wall between two adjacent cells of the same structure is to be accomplished.

We must note here at once that the processes described are not at all of the nature of a secondary fertilization. The presence of the receptive spot at the apex of the conjugating tube shows that the latter is an organic part of the oogonium, and that it is the fusion of tube and antheridium which is homologous with the fusion of egg and sperm in Oedogonium or Vaucheria, while the breaking down of the basal wall of the tube is a later development necessitated by the formation of a conjugating tube on the oogonium. However, under the conditions found in Pyronema both fusions are necessary for fertilization, and the question is merely one of homologizing the processes here with those in oogonia, where no beak-like conjugating tube is present; and as already noted, from this standpoint there can be no question that the possession of a conjugating tube on the oogonium is a later and more specialized condition than that in the Algae named, and that the conjugating tube is merely a portion of the oogonium set apart for the conduction of the male nuclei to the egg-nuclei. The nuclei of the tube are therefore potential egg-nuclei, and their disintegration is physiologically analogous to the disintegration of potential eggs as nurse-cells, \&c., which is seen in so many cases in the ovaries of animals.

We may conclude then that although we have two cellfusions, i. e. first, the fusion of the antheridium with the tube, and second, the fusion of the compound cell so formed with the oogonium, these are not to be interpreted as two fertilizations. The contents of the tube-cell are entirely passive after the fusion-pore has been formed, the real and only 
fusion of protoplasmic substances for purposes of reproduction being that between the antheridium and oogonium.

The passage of the antheridial nuclei through the tube into the oogonium, when once the way is open, is a rapid one. As has been seen already the tube is filled with antheridial nuclei before its basal wall is dissolved. The opening formed is larger than that between antheridium and tube, the entire basal wall of the tube being disintegrated. As a result there is an actual protoplasmic continuity between the male protoplasm in the tube and the egg-protoplasm. The two masses fuse at their point of contact after the tube wall has disappeared, so that the male nuclei enter the oogonium not like so many independent sperms, each piercing the plasma-membrane of the egg, but by simply migrating from the one cell-body to the other through a continuous mass of protoplasm. The entire structure, antheridium, tube, and oogonium, have in reality become for a time a single cell bounded by a single continuous plasma-membrane.

In passing into the oogonium, the male nuclei leave behind the bulk at least of the cytoplasm with which they have been associated. The cytoplasm of the antheridium has been carried to some extent into the conjugating tube, but for the most part it remains in the antheridium. The nuclei here, as in so many other cases, indicate their superior significance in sexual reproduction by leaving behind the cytoplasm which has hitherto been associated with them.

One conspicuous result of this non-participation of the cytoplasm in the act of fertilization is, that the antheridium and conjugating tube remain turgid and to the superficial view unchanged for a long period after the fusion has taken place. Tulasne observed this and remarks, as referred to above, that if the macrocyst and paracyst do influence each other mutually, this at least produces no notable change in their external appearance. As seen in sections the antheridium contains a series of large vacuoles in its central portion which were not present immediately before the migration of its nuclei (Figs. 1 5, 17, 20, and 21). The presence of these 
vacuoles however does not constitute a very noticeable change as seen in the living cell, especially since in its earlier development the antheridium is decidedly vacuolar. It is interesting to see that the actual process and nature of fertilization in Pyronema could not have been discovered by the earlier observers, to whom the nuclei were invisible since it is practically the nuclei alone which pass over from the male to the female cell.

The number of male nuclei which enter the oogonium does not appear to be exactly the same as the number of egg nuclei to be fertilized. I have counted them in several cases and found upwards of two hundred in each sexual cell. It is difficult to see, since oogonium and antheridium are each developed from a multinucleated cell to start with, and there is no evidence subsequently of a parallel series of nuclear divisions in each, how exactly the same number could be provided in each case. As a rule when fertilization is accomplished by free motile male cells the latter largely outnumber the eggs. There is here no necessity for such excess, and the numbers, as I have pointed out, appear approximately equal. It will be seen however later that there is good evidence of slight inequality in the number on one side or the other, and that these supernumerary nuclei die without further development. It should be mentioned in this connexion that there is quite commonly an excess of antheridia. I have frequently found two antheridia applied to the surface of one oogonium, but only in one case have I found them in connexion with it (Fig. 2I). In this case the conjugating tube was forked, sending a branch to each antheridium as the figure shows. Kihlmann describes a branching antheridium connected with two oogonia. The supernumerary antheridia are abundantly filled with nuclei and seem normal in every respect. They do not however develop further, and may be found very frequently at a late stage of development protruding from the base of the hypothecium with their contents quite unchanged, except for the aggregation of their nuclei at the apex of the cell. This is at a time when the 


\section{Harper.--Sexual Reproduction in Pyronema}

functional sexual cells are entirely emptied of their contents. They thus furnish very interesting evidence of the sexual nature of the fusions, in that they show that the cells concerned are incapable of further development if the fusion fails to occur.

In view of what is described below of the fusion of nuclei in the oogonium this kind of evidence seems hardly necessary. Still, in discussing conidial fusions in the Smuts, Brefeld (5) has insisted especially upon the inability to develop further without fusion as a final test of the sexual nature of cells, and in these supernumerary antheridia we have a most striking example of this particular sort. Ultimately the contents of these antheridia disorganize into an undifferentiated deep staining mass which then becomes a prey to Bacteria and disappears. Brefeld doubtless overestimates the value of this sort of evidence, as I have endeavoured to show in another connexion above.

How such waste of material comes to occur, when one might suppose the development of a single oogonium and antheridium together could be correlated from the beginning of the development of a fruiting cluster, is not so easy to understand. Such duplication of the antheridial branches never occurs in the Mildews so far as I have observed. It may be that this want of correlation is to be taken as indicating that the sexual cells arise from rather widely separated branches of a mycelium if not from branches arising from different mycelia.

The complete migration of the male nuclei into the oogonium represents the usual case; still, it is not very uncommon to find a few nuclei left behind either in the antheridium or the conjugating tube. The significance of this latter condition will be discussed later. After the migration of the male nuclei is complete a wall is built across the base of the conjugating tube, cutting off the oogonium once more as a single spherical cell. On the other hand the pore between the antheridium and conjugating tube remains permanently open and can be readily recognized in all the subsequent growth 
of the ascus-fruit until the entire sexual apparatus collapses at a late stage in development. The fusion of the conjugating tube with the oogonium is thus relatively transitory when compared to its fusion with the antheridium, and herein doubtless is the reason why Tulasne and Kihlmann failed to discover the former fusion while perfectly familiar with the latter. The reason for rebuilding the wall in one case and not in the other is perfectly apparent in that the oogonium is to develop further, while the functional activity of the antheridium and conjugating tube is completed with the accomplishment of fertilization.

The male nuclei, as has been noted, on entering the oogonium mingle with the egg-nuclei in the more or less central group into which the latter have collected. The nuclei are indistinguishable in size, structure, and staining qualities, so that it is quite impossible to pick out a single nucleus at this stage and say with certainty whether it has come from the oogonium or antheridium originally. We have simply a mass of scores of nuclei which have been brought together in the manner just described. These nuclei fuse in pairs, while they are yet aggregated in the dense mass described above. Fig. 15 shows a section of this mass at a stage when many of the fusions are complete. Fig. I $5 a$ shows a section from another oogonium in which most of the pairs have fused. The mass is so dense at this stage as to make the study of the individual nuclei in its centre quite difficult even in very thin sections, but at the margin of the mass, and in tangential sections from its surface numerous pairs of nuclei can be found in various stages of fusion. Parts of such tangential sections showing fusing nuclei in various stages and from different oogonia are shown in Figs. $16,16 a$, and $16 b$. Fig. 16 is from an oogonium with a crescentshaped mass of nuclei. The other two are from oogonia with spherical masses of the type shown in Figs. ${ }_{5} 5$ and $\mathrm{I}_{5} \alpha$. Although the nuclei from the antheridium are not distinguishable in size or appearance from those already in the oogonium, still there seems no reason to doubt that such

$\mathrm{B}$ b 2 
fusing pairs consist in all cases of male and female pronuclei from the antheridium and the oogonium respectively. It is also impossible, as I have just mentioned, to determine with certainty the behaviour of the nuclei in the centre of these masses ; still, the large number of cases of fusion that can be observed leaves little doubt that the rule of fusion in pairs holds for practically the whole mass.

It will be observed that these fusions are not necessarily simultaneous, some pairs being completely united while other nuclei are not yet arranged in pairs. In the oogonium from which Fig. 15 is taken, it is to be seen in other sections that a few nuclei have already begun to wander out into the young ascogenous hyphae, while the ascogenous hyphae of the oogonium, from which Fig. $15 \alpha$ is taken, contain as yet no nuclei.

It is not to be assumed from my statement as to the density of this mass of nuclei in the oogonium that anything in the nature of a general fusion of the nuclei into a single nucleus occurs. It is perfectly certain, as seen from my Figs. I 5 and I $5 a$, that throughout these masses individual nuclei of typical appearance can be made out with perfect certainty and at a slightly later stage, when the nuclei scatter after fusion, it is still further apparent that the mass consisted of perfectly distinct nuclei (Pl. XX, Figs. I $7 a, b)$.

This aggregation of the nuclei at the time of fertilization seems to be simply a provision for the pairing of the male and female nuclei with the greatest certainty and dispatch. If the sexual nuclei are attracted to each other chemotactically, it is easy to see that unnecessary migrations of the male nuclei after attempts at multiple fusions are avoided by having the female nuclei in close proximity with each other, and in as small an area as possible. If the female nuclei were irregularly distributed it would be possible that isolated unpaired male and female nuclei might remain at opposite sides of the oogonium outside the spheres of their mutual chemotactic influence. Pyronema thus affords an interesting example of the fusion of multinucleated sexual cells and the 
subsequent pairing of the male and female nuclei in the oogonium. The more general significance of these phenomena I shall discuss further on.

While the conjugating tube is still in open connexion with the oogonium, and in some cases even earlier than this, we find papillae budding out over the lower surface of the oogonium. The base of the oogonium is also enveloped at this stage with the vegetative branches which are to develop the hypothecium (Figs. I4, I5). These vegetative enveloping hyphae are not distributed evenly around the whole base of the oogonium. To understand their arrangement fully the study of more or less nearly horizontal sections through the rosettes of reproductive cells is necessary. Fig. I8 shows such a section at an earlier stage prior to fertilization, and from it a number of facts can be made out as to the relation of the oogonium and antheridium to each other, and also as to the relation of the pairs of sexual cells to each other in the cluster. This section shows three pairs, which is perhaps a fair average number for the form of the Fungus I have studied. It is seen at once that the oogonia are arranged in a triangle and that the antheridia are turned toward their outer surfaces. This is quite a universal rule in the cases examined. While the antheridium may originate at almost any point near the base of the oogonium, it almost without exception takes a path in its growth which brings it to that side of its oogonium which is turned away from the other oogonia of the group. It can be seen, further, that in one case almost the full length of the conjugating tube can be seen although the section is inclined at a considerable angle to the vertical, showing that the axis of growth of the oogonium and tube is not a vertical line but is inclined outward from the base of the median vertical axis of the group. The distribution of the hypothecial hyphae can here be readily seen, and it is interesting to note that the young vegetative filaments which are to form the hypothecium and paraphyses are all growing upward between the oogonia of the group so that the outer surfaces of the latter are left entirely un- 


\section{Harper.-Sexual Reproduction in Pyronema}

covered. This inequality in the distribution of the enveloping hyphae may continue through their entire development. As they become more numerous in most cases they gradually spread around the base of the oogonium for about one-third of its height, leaving still exposed a large oblique circular segment of its surface. As a result of this habit of growth we have in the mature fruit-body a series of these exposed oogonial surfaces bulging out around its base, enclosed by a fibrous network of the vegetative hyphae. Sections of the fruits of course show these exposed oogonial surfaces only when they lie in a plane cutting such an exposed surface in a radial direction (Fig. 23 to the left). In other cases the sections may show the oogonia entirely (Fig. 20), and in some cases equally enclosed on all sides. In old fruits the secondary mycelium, as described below, forms a more or less perfect envelope around all these structures.

The vegetative hyphae developing in connexion with each of the whole number of oogonia of a cluster, whatever it may be, become combined in a single apothecial fruit-body as has been observed by all the earlier investigators of Pyronema. Such an ascocarp has been called a compound apothecium or syncarpium as compared with the ascocarp of Erysiphe which develops from a single ascogonium. Very frequently the rosettes of sexual organs grow so close together that further combination occurs by contact of adjacent ascocarps so that crusts or turfs of considerable extent may be formed.

It is, however, by no means unusual to find single isolated pairs of sexual cells and from these equally perfect simple apothecia develop. These simple apothecia are not, however, symmetrically developed around the original axis of growth of the oogonium. The vegetative hyphae always develop on one side of the oogonium so that a portion of one side of the latter is exposed near the base of the hypothecium just as in the case of the compound fruits.

At an early stage (Fig. I4) the vegetative enveloping hyphae have enclosed the oogonium quite fully on all but a portion of its outer and upper surface. The hyphae are several layers 
thick and into this mass the papillae mentioned above as forming on the basal region of the oogonium push out (Fig. I9). These papillae are the young ascogenous hyphae. On the free outer surface of the oogonium many of them arise at a higher level than the vegetative hyphae have reached, and grow out a short distance free and unenclosed (Figs. I 5, I $5 a$, and 17 ). These branches contain no nuclei at first.

At the time when the ascogenous hyphae first appear, the nuclei are still massed in the centre of the oogonium. As soon, however, as the fusion of the majority of the pronuclei is complete the dense mass begins to loosen up. This is well shown in two sections taken from different parts of the same oogonium (Figs. I7 $a$ and $b$ ). At this stage the nuclear fusions are practically all complete. The nuclei are rounded up and show no trace of the fusions by which they were formed except an increase in size in some cases.

From the completion of the fertilization stage onward, the oogonium may be known as an ascogonium. It enters upon a renewed stage of vegetative activity which was made possible as a result of fertilization. In Pyronema, as we have noted, the ascogenous hyphae spring directly from the oogonium without its first developing into a multicellular organ as in Sphaerotheca and Erysiphe. This is, however, a minor difference; the fact that there is a period of renewed growth beginning at the time of fertilization and leading to ascusformation, justifies the retention in all cases of the term ascogonium for the body from which the ascogenous hyphae spring. The scattering of the nuclei in the ascogonium is very rapid, as evidenced by the appearance of fusion-nuclei in the young ascogenous hyphae (Figs. $17 a$ and $b$ ) which when they were only a trifle shorter contained none (Fig. I $5 a$ ). It is also very apparent at this stage that the massing of the nuclei in the centre of the oogonium was not at all in the nature of a fusion. As soon as the fusion in pairs is complete each nucleus appears with perfectly sharp contours in the loosening mass. The fusion-nuclei at this stage show much more conspicuously differentiated nucleoli than did the pro- 


\section{Harper.-Sexual Reproduction in Pyronema}

nuclei. The chromatin is also sharply differentiated in the form of strands or granules on the inner surface of the nuclear membrane, or distributed in the nuclear cavity (Figs. $17-20$ ).

The ascogenous hyphae continue their growth and the ascogonium is rapidly emptied of its nuclei and protoplasm (Fig. 19). These ascogenous hyphae are extremely crooked and soon become septate. At first they may grow downward as it were to meet the developing vegetative hyphae among which they wind about in the most intricate fashion, as is only partly shown in Fig. 19. This preliminary downward growth would seem to indicate that in some degree the ascogenous hyphae anticipate in their development the vegetative paraphyses with which they are to be associated. It is probably true that the greater ease with which the ascogenous hyphae can push in among the vegetative hyphae at this early stage, more than compensates for any loss resulting from the detour they make in turning downward at first instead of growing directly upward toward the position of the future hymenium.

After the ascogenous and vegetative hyphae have become thoroughly interwoven, a rapid stretching upward of the whole mass ensues. In this growth the vegetative hyphae outstrip the reproductive ones and form at first a cone-shaped mass made up of their elongated slender, densely aggregated tips. These elongated upper extremities of the vegetative hyphae of the envelope are the young paraphyses. Their number is being constantly increased by the pushing in of new branches from below, and thus the cone-shaped outline is maintained. The ascogenous hyphae grow upward for a certain distance in company with the vegetative hyphae. Their growth upward then ceases and they spread out horizontally, forming a rather dense layer at the base of the cone of paraphyses which may be called, if we restrict the term somewhat from its usual significance, the sub-hymenial layer. This interwoven horizontal layer marks the base of the hymenium. It is a little below the level of the point of union of the conjugating tube and antheridium (Fig. 20). 
The paraphyses also show a limited apical growth, and having reached a height above the layer of ascogenous hyphae about equal to one-half the total thickness of the hypothecium, they also cease to grow in length and remain as a densely packed mass of parallel slender hyphae containing numerous minute nuclei in a vacuolated protoplasmic mass. They are septate and of about equal diameter throughout their entire length.

The ascogenous hyphae follow such irregular paths from the ascogonium to the hymenium that it is impossible to follow any one of them continuously for any great distance in a single section. They appear in the sections at this stage cut transversely and longitudinally in fragments of various lengths. They can always be distinguished from the vegetative hyphae with which they are intertwined by the size of the nuclei which they contain (Figs. 19, 20). The fusionnuclei contained in the ascogenous hyphae have always a diameter two or three times as great as that of the nuclei of the vegetative hyphae. This makes the recognition of the ascogenous hyphae an easy matter, so that it is possible to trace their distribution anywhere in the fruit-body, as will be seen from Fig. 20.

In the stages after fertilization, as the central mass of nuclei becomes more distributed and the number of nuclei in the ascogonium is reduced by their migration into the developing ascogenous hyphae, nuclei of smaller size are frequently found mingled with the larger fusion-nuclei (Figs. $I 7$ and 20). In some cases these smaller nuclei can also be found in the ascogenous hyphae (Fig. 20 a). They are the size of the original nuclei of the oogonium and antheridium. Fig. 22 shows an ascogonium in a stage when the young asci are forming, a little older than the stage shown in Fig. 20. The contrast in size of the nuclei still in the ascogonium is seen to be very striking. I am of the opinion that the smaller nuclei in this case represent supernumerary oogonial nuclei which have not been fertilized and are incapable of further development. Their remaining unfertilized 


\section{Harper.-Sexual Reproduction in Pyronema}

may have been due to the numerical inequality between the nuclei of the oogonium and antheridium, the lack in this case being on the part of the antheridium. They would then represent unfertilized egg-nuclei. It is evident they are incapable of further development since they are never found in the sub-hymenial layer of the ascogenous hyphae or in the young asci. In some cases they may be found in cells of the ascogenous hyphae as noted above, but never very far removed from the ascogonium. I am of the opinion as I have said that these are oogonial nuclei. It is, however, quite possible that they may be antheridial nuclei which found no egg-nuclei with which to fuse. This latter hypothesis would harmonize better perhaps with the general tendency in plants and animals to produce a larger number of male cells than of eggs. It was, however, noted above that in some cases a few nuclei were found in the antheridium after fertilization is complete and this has led me to assume that probably when an excess of male nuclei is present they are left in the antheridium. The chemotactic or other stimulus which leads the male nuclei to migrate through the tube to the oogonium would in this case be assumed to have exhausted itself when a number of the latter equal to the number of egg-nuclei had reached the oogonium. Whether these small and apparently unpaired nuclei found in the oogonium are male or female pronuclei, they do not develop further, and this fact is suggestive as to the necessity for fertilization and the impossibility of purely vegetative or parthenogenetic development on the part of the sexual nuclei in Pyronema. Ultimately these nuclei in the ascogonium become flattened upon its wall in an extremely thin layer of cytoplasm which is always found in it until a late stage of development. In the old fruits the nuclei and cytoplasm both are disorganized and appear as more or less scattered deeply stained granules.

If we turn now to the development of the asci from the ascogenous hyphae of the sub-hymenial layer we shall find nothing essentially different from what I have already 
confluens and the Morphology of the Ascocarp. 363

described for Peziza, Lachnea, Ascobolus, and Erysiphe. The young asci of Pyronema, like those of the Mildews, contain regularly two nuclei. The origin of these nuclei can be readily traced in Pyronema. The ascus here is quite regularly an outgrowth of the penultimate cell of the ascogenous hypha which bears it. Dangeard (7) has described this method of origin quite fully for Peziza vesiculosa, though he still says that the ascus may in some cases be the product of the fusion of separate hyphae. When the ascus arises from a single hypha he finds in the latter at first a single nucleus. This divides into two nuclei. Later a second nucleus appears which also divides into two. Of these four nuclei two are destined to fuse in the young ascus, one remains in the apical cell, and one in the cell behind that which develops the ascus. I find in general the same phenomena in Pyronema though, as will be noted below, the division of the two nuclei always occurs simultaneously.

The tip of the ascogenous hypha pushing up among the paraphyses becomes recurved. In this hypha we have a period of nuclear division. It at first contains two nuclei which divide into four nuclei. The divisions of the two nuclei are exactly simultaneous as seen in Figs. 25-29. The spindles are so placed that a pair of nuclei are left in the bent part of the hypha, a third lies in the recurved tip, and the fourth lies farther back in the hypha just below the point at which it bends (Pl. XXI, Figs. 29, 30).

The recurved tip is then cut off by a cross-wall (Fig. 31 ), and a second wall is formed parallel to, or at a slight angle with the first, and generally at about the same level, cutting off the hypha just below the bend. The dome-shaped cell formed in this way at the bend in the hypha is to develop the ascus. It contains two nuclei, and from the position and orientation of the spindles in Fig. 29 it is seen at once that they are not sister nuclei, and are each derived from a different one of the original pair of nuclei in the tip of the hypha. Whether these latter nuclei are formed from a single one of the fusion-nuclei by division I have been unable to deter- 


\section{Harper.-Sexual Reproduction in Pyronema}

mine with certainty. The only nuclear divisions I have seen in the ascogenous hyphae of Pyronema are the simultaneous divisions in the hyphal tips just referred to. These divisions are very readily observed and can be found in great numbers. It would seem if the paired nuclei arise by division of a single fusion-nucleus, that the nuclear figures should be readily found, but I have been unable to discover them.

Pyronema presents in the development of its ascogenous hyphae unusually simple conditions. The apothecia are very small and the total number of asci produced is not greater than could be provided for in the manner described without increase in the number of nuclei beyond those which are fertilized in the oogonium. In larger forms like Peziza, where the apothecia continue to grow in diameter for a long time, the conditions may be very different, and nuclear multiplication in the hyphae may probably provide for the development of the successive series of asci formed. It is to be remembered, too, that several ascogonia in Pyronema contribute ascogenous hyphae to the same apothecium.

The fate of the sister nuclei to those enclosed in the ascus is not certain. Dangeard seems to consider that the apical recurved cell of the hypha shows no further growth, though he is not very explicit on this point. I have never found evidence of this apical cell developing further. I have found frequent cases where it had degenerated, and it is safe to assume that this is the rule. As to the fate of the fourth nucleus I have found a number of preparations which show that in Pyronema, at least in some cases, it also does not develop further. Fig. 3I shows that the fourth cell from the hyphal tip produces the second ascus, the third cell containing the nucleus in question remaining sterile. The second ascus is formed just as the first was, the fourth hyphal cell pushing out into a lateral branch whose tip becomes recurved, just as in the first case. In the case figured the nuclei in the second branch are two in number and are in the equatorial plate stage. If the same plan were carried further back it might be the fifth cell which would produce the next ascus, the sterile cell in this 
case being the basal cell of the lateral branch bearing the second ascus. I doubt, however, whether such a series could be found. The ascogenous hyphae produce such numerous short branches in Pyronema that I have never been able to find more than two asci connected in the fashion shown in Fig. 3I. Such a system is doubtless itself a lateral branch. The formation of the asci is, however, clearly basipetal, as has been pointed out many times, and this makes it still more improbable that the apical recurved cell develops further after the first ascus is formed.

In brief, then, of the four nuclei formed by the divisions of the two fusion-nuclei, two in the case described undergo no further development. The other two, lying in the young ascus, fuse to form the nucleus of the ascus. Such a pair of fusing nuclei are shown in Fig. 33. The nuclei become somewhat enlarged before fusion occurs, the dome-shaped cell in which they are enclosed at first pushes out at its apex into a club-shaped process, which grows rapidly in length and becomes the ascus, which is thus supported on two cells at its base (Figs. $3^{1}$ and $3^{2}$ ). The two nuclei lie side by side or one above the other in the young ascus when they fuse. They become slightly flattened upon each other, their membranes disappear at the point of contact, and they form thus a single nucleus which is first oblong and becomes gradually spherical or oval (Fig. 34). This behaviour of the nuclei at the time of the formation of the ascus has not been as yet satisfactorily explained. Dangeard's hypothesis, that the ascus is an oogonium, is certainly not established, and as it was developed by its author without any investigation of the origin of the ascocarp or knowledge of the existence of nuclear fusions in its early stages, it can hardly be considered as applying to Pyronema. I shall further discuss the question of the significance of these fusions later on.

The phenomena of nuclear division and spore-formation in the ascus of Pyronema differ only in details from what I have already described for a number of forms. As it seems worth while, however, to have a complete account of the develop- 
ment of forms like Pyronema, which have become familiar through their use as types in the text-books, I shall give a description of the main stages in the development of the ascus and the ascospores.

In the young ascus the protoplasm is rather evenly distributed, and the nucleus lies a little above the middle point of the long axis (Fig. 23). As the ascus increases in size a special denser mass of protoplasm, which is to form the spores, is differentiated in its upper portion. In the mature ascus this denser protoplasm is bounded above and below by a concave surface, and the remainder of the ascus is filled by a very vacuolar foamy protoplasm (Figs. 39, 40). The nucleus lies at first near the base of this denser mass. It is a large conspicuous structure with a single bright red-stained nucleolus and an irregular chromatin net. Fig. 35 shows an equatorial plate stage of the division of this nucleus. It is to be noted that this primary nucleus does not tend to occupy the centre of the dense protoplasm in which it lies. The two secondary nuclei into which it divides are also not arranged symmetrically as they are in the ascus of Lachnea for example. In Pyronema these two nuclei generally lie close together in a line which cuts the long axis of the ascus at a considerable angle. They remain in this relative position while dividing. Figs. $37,3^{8}$ show equatorial plate and dispirem stages of this second division. The daughter nuclei are still connected by the remnants of the spindle-fibres which have been drawn out into a narrow strand in Fig. 38 . In this figure two nucleoli appear in the cytoplasm in the position of the nuclei before their membranes were broken down.

The four nuclei resulting from the second division become arranged in a symmetrical row in the long axis of the ascus (Fig. 39). The spindles of the third division lie more or less transversely, so that the eight daughter nuclei formed are at first in an irregular double row, all of them within the mass of denser cytoplasm.

The daughter nuclei of the eight-nucleated stage as in Lachnea are completely reconstructed before the beaks are 
formed. The polar asters are persistent after the last division as in other cases I have studied, and when the beak is formed on the nucleus the aster lies at its tip. The structures at this stage in Pyronema are quite small, but all the principal stages in the transformation of the aster into a plasma-membrane for the ascospore can be readily distinguished. Fig. 40 shows an exceedingly common stage in which the beak is formed, and the aster is apparently flattened somewhat against the wall of the ascus. In the case of three of the nuclei in this ascus the axis of the beak was so nearly vertical to the plane of the section that it is not represented in the figure. The nuclei are in the resting condition and fully developed. They contain a single nucleolus as a rule, and the chromatin is in the form of irregular granules and rods, or even threads. The dense mass of protoplasm in which the nuclei are lying is entirely without indication of its future differentiation into spore-plasm and epiplasm. At the upper end of the ascus above the region where the spores are to be formed it is loosely spongy and vacuolar in texture. The same condition is found in the ascus below the spore-bearing region, but is not shown in the figure.

Fig. 4I. shows a later stage in the spore-formation also very common in Pyronema, though not so common in the forms hitherto studied. We have here a stage when the spores are about half surrounded by the folded back rays of the aster. The rays are already fused to a membrane about the point of the nuclear beak as shown by the slight plasmolysis in the case of the lowest of the forming spores in the Figure. In two cases here also the beak does not appear because it stands too nearly vertical to the plane of the section. In both these cases, however, portions of the forming plasma-membrane appear in the positions where they are to be expected partly encircling the nuclei. The amount of material in the asters and developing membranes in this ascus is plainly much greater than is present in the stage represented in Fig. 40, and indicates, as I have pointed out before (16) that new kinoplasmic material may be formed 


\section{Harper.-Sexual Reproduction in Pyronema}

during the process of cutting out the ascospore. Probably the nucleus with the beak is a centre for this metabolic activity, the kinoplasmic material being distributed from the point of the beak as I have endeavoured to show more fully elsewhere. The process of growth of the rays and their fusion into a membrane continues backward around the nucleus until the latter is entirely enclosed in a new bounding membrane, and the spore is thus completely deliminated by the process of free cell-formation. Later, a wall is developed around the spore, which in Pyronema never becomes especially thickened or sculptured. The ripe spores remain uninucleate. Their germination I have not studied.

A section through a mature compound apothecium is shown in diagram by Fig. 23. The secondary mycelium shown at this stage begins its development as an outgrowth from the superficial cells of the hypothecium in stages a little older than that shown in Fig. 20. These filaments may arise from any one of the hyphal cells which is on the surface. They are extremely thick, at least twice the diameter of ordinary filaments, and extend downward and outward until they reach the substratum, where they mingle with the hyphae of the mycelium. Their existence is necessary for the support and attachment of the fruit-body, since it would otherwise have only the original thickened hyphae of the cluster which bore the sexual organs as a connexion with the substratum. Whether these appendages also serve to draw up water and food from the substratum is uncertain. Their protoplasm is vacuolated. They are sparingly septate, and their cells are multinucleate. They are plainly similar to the supporting hyphae I have already described for Ascobolus (16), and are probably homologous with the more highly differentiated appendages of the Mildews. As already noted, the apothecium of Pyronema is a compound structure built up of the ascogenous hyphae and vegetative tissue developed in connexion with several pairs of sexual organs. Fig. 23 represents two ascogonia at the base of the fruit-body. In such cases as this it is very plain that the main development of the asco- 
genous hyphae and paraphyses from any one oogonium and its stalk is always to one side of the oogonium and never about it as a centre. As noted above, the several oogonia of a cluster always develop their branches on their adjacent sides as far as possible so that the centre of development of the apothecium is the centre of the cluster of reproductive organs. In this way symmetrical circular apothecia are developed similar in appearance in all respects to the fruitbody of Ascobolus, which develops from a single ascogonium.

Such irregular masses, as are shown in Fig. 98 of De Bary's text-book (13), I have never found arising from a single rosette, but by fusion of the fruit-bodies from a series of rosettes crusts can be formed of considerable size and extremely irregular outline.

When, as I have noted above, a single pair of sexual cells develops a fruit-body, it is always unsymmetrically placed with reference to the oogonium which lies exposed on one side of the hypothecium. This shows that the development of the ascogenous hyphae and paraphyses chiefly on one side of the oogonium is not merely a correlation of the formation of the compound fruit-body. The true explanation is probably that the oogonium is too large relatively to the size of the entire fruit to be properly enclosed by the hypothecium without distortion of the hymenium and the formation of a poorly developed point in its centre. Hence the oogonium is left at one side, and its branches with the vegetative hyphae develop a symmetrical, somewhat topshaped apothecium.

Pyronema belongs to that group of the Discomycetes in which the hymenium has no peridium or lateral boundary of vegetative protective hyphal tissue around the hymenium. This condition is very well shown in sections (Figs. 20, 23), the paraphyses being seen to form the outermost boundary of the hymenium on its entire periphery. This character in Pyronema is probably correlated with the habit of producing compound apothecia and still larger crusts by fusion. It would be plainly a waste of material to attempt to delimit 
by a vegetative layer the particular ascogenous branches that come from each pair of sexual organs.

As in the other forms studied, the ascogenous hyphae are relatively transitory structures in their basal portions, and maintain no permanent system of connexions for the transfer of food from the ascogonium to the developing asci. The ascogonium persists longer than do the ascogenous hyphae, but it is merely an empty sac. The ascogenous hyphae can hardly be found in an old fruit. They have simply collapsed from the pressure of the growing vegetative hyphae around them. In the sub-hymenial layer the tips of the ascogenous hyphae continue to grow and branch until the fertilized nuclei are all utilized in forming asci. The collapse of the ascogenous hyphae at a relatively early stage indicates that it would be quite difficult for the asci to be nourished through them from below. The development of the asci is relatively slow, and, as I have noted in other cases, all the conditions indicate that the asci get their nutriment through their walls from the adjacent paraphyses.

The fact that not all the asci develop simultaneously necessitates the continued development of paraphyses from the hypothecium to provide for the later-developing asci. A special type of hypha has been developed in Pyronema to provide these late-developing paraphyses. These hyphae arise from the basal cells of the cluster or the stalk-cells of the oogonia, and push up among the vegetative hyphae of the hypothecium. They then become divided by septa into short cells which immediately swell into large spherical or barrel-shaped vesicular reservoir which, as fast as they swell, are packed full of protoplasin with numerous nuclei. This protoplasm is unusually dense. The diameter of the reservoir cells is twice or three times that of the ordinary hyphae, and altogether they are very conspicuous objects (Figs. 23, 24). In free-hand sections not stained to show the nuclei one would very naturally pick out these hyphae for the ascogenous hyphae. It is easy to prove, however, that they contain only vegetative nuclei, and are ultimately de- 
veloped above into paraphyses. I have pointed out above that Krabbe in his work on Cladonia may very likely have mistaken some form of storage hyphae, such as those I have described, for the ascogenous hyphae, and thus have been led to the false conclusion that ascogenous hyphae and paraphyses are ramifications of the same vegetative system. In stained microtome sections of Pyronema there is no necessity for such a mistake. The ascogenous hyphae develop much earlier than these swollen hyphae, and have largely disappeared in the lower part of the hypothecium when the latter appear. The nuclei also furnish an unfailing criterion, those of the ascogenous hyphae being two or three times the diameter of those in the vegetative hyphae. Furthermore, the ascogenous hyphae never appear as densely packed with protoplasm as do these vegetative cells.

The protoplasm of these swollen cells is finely differentiated in their central parts into a system of fibres which extend from one septum to the next (Fig. 24). These fibres are curved so that when taken together they form a strongly swollen barrel-shaped figure. This system of fibres is very prominent in the cells in question. Its interpretation is not easy. Perhaps the fibres represent paths along which materials are transported from one cell to the next. The piling up of protoplasm in these cells doubtless requires considerable transportation of foods from one cell to another, and this may possibly have led to the very conspicuous differentiation of these fibrous tracts. Whether there is actual protoplasmic continuity, or even protoplasmic contact, between these cells by means of pores $\therefore$ their septa I have not determined. Ultimately these vesicular cells become emptied of their protoplasm and appear as other hyphal cells of the hypothecium except for their much larger size.

\section{General Conclusions.}

If we interpret the phenomena I have described as occurring in the antheridium and oogonium, in the light of what is 


\section{Harper.-Sexual Reproduction in Pyronema}

known of sexual fertilization elsewhere, the conclusion is inevitable that we have here also a true sexual reproduction. Cells of separated origin fuse by means of the breaking down of cell-walls and the union of protoplasmic masses at the point of contact, and this protoplasmic union is followed later by a pairing of the nuclei. These facts are conclusive as to the homology of the processes here with the sexual processes in Cystopus, Oedogonium, Nemalion, Batrachospermum, \&c., and it seems hardly necessary to discuss the assertion that such fusions are the same as those which occur between the ordinary vegetative hyphae of a.mycelium. I have discussed the significance of these latter fusions elsewhere (17), but it only needs a moment's consideration to show, that they have no direct relation with the sexual conjugation I have above described. These mycelial fusions are not between specially differentiated hyphal cells. They occur at no definite point in the life-history of the Fungus, and lead to no specific fruit-formation. Indeed the comparison is so shallow and unenlightening, even on the basis of Tulasne's original description of the fusion in Pyronema, that it is hardly worthy of a detailed consideration.

Van Tieghem (37, p. I 66 , note) has brought forward the argument that the methods of sexual reproduction, as described for the Lichens, Mildews, Eurotium, Pyronema, \&c., are too varied to be found in related genera of such a group as the Ascomycetes. Such a priori arguments are of very little value in connexion with a subject so little investigated as the sexuality of the Ascomycetes, in which the number of forms whose ascus-fruit development has really been thoroughly investigated is so small in comparison with those in which, because of their small size or the difficulty in separating the Fungus from its substratum, \&c., the course of this development in its earlier stages is largely unknown. For the present we shall have to admit that whether it is reasonable or not there are in the true Ascomycetes at least such types of sexual apparatus as have been described for the Laboulbeniaceae, the Lichens, the Mildews, and Pyronema. It is 
not improbable that further investigation will show connecting links between these forms, but that is entirely a matter for investigation rather than speculation.

Van Tieghem also suggests (37, p. I I 42) that the swollen oogonium and the antheridium in Pyronema are only reservoirs of stored food material brought together by the hyphae at certain points in anticipation of unusual outlay in rapid growth during fruit-formation. In view of the behaviour of the nuclei of these cells as I have described it above this interpretation becomes quite inadequate. Female sexual cells are commonly well stored with reserve food-materials, but no one will seriously contend that they are to be explained merely as reservoirs for storage.

Van Tieghem's hypothesis was without foundation on the evidence which had already been submitted by Kihlmann, who showed that only the ascogenous hyphae are developed from the specially swollen cell, while the whole hypothecium and paraphyses arise from mycelial cells below the sexual apparatus. Bauke had already pointed out that the asci are nourished from the paraphyses, and all observers had agreed that the ascogonium withers at a relatively early stage. Surely it was unreasonable to assume that an organ specially developed as a reservoir of nutrition should fail midway in the completion of its function, not even serving in its later stages as an avenue for the conduction of new food-materials to the asci. It seems not too much to claim that the opponents of sexuality in such forms as Pyronema seem to have been bent on overlooking the more obvious facts in the interest of ingenious but unreasonable hypotheses.

The investigation of the sexuality of the Fungi has become involved to an unusual degree in the personal animosities of rival investigators, and as a result De Bary's pre-eminence, as the first who attained the technical skill necessary for grappling with the problem, has been too little recognized. De Bary and his pupils brought together a greater mass of accurate and detailed observations on the life-histories of the forms in question than any or all of the opponents 


\section{Harper.-Sexual Reproduction in Pyronema}

of his views can muster. Opposition to his view of the nature of the ascus-fruit in the forms he studied has not been based to any appreciable extent on detailed investigations of the development of these structures in the same or in related forms, but rather on a general scepticism as to the accuracy of De Bary's observations, and on vague and fanciful hypotheses such as those referred to above. De Bary's generalization, as to the sexuality of all the Ascomycetes from the relatively few forms he had studied has been much criticized as based on too few observations. Still it is to be noted that no successful attempt has ever been made to subdivide the group in question. Regarding the group as a phylogenetic unit it was and is quite justifiable to assume that such similar structures as the ascus-fruits must be homologous, and if in one case their initial organs are a sexual apparatus, whether functional or not, the assumption is, until the contrary is proved, that the same will be true for the other members of the group, all due allowance being made for a possible suppression or further development of any particular stage in special cases. So long as there is no evidence from other sources on which to subdivide the group there is the strongest probability that the ascus-fruits of all Ascomycetes are morphologically equivalent to the ascus-fruits of Sphaerotheca, Pyronema, and the Lichens.

The opponents of De Bary's views, apart from Dangeard, who so far stands alone, have shown no less certainty of the unity of the group than did De Bary, and have concluded that the entire group is without sexual reproduction, because they believe functional sexual organs are lacking in some specific cases, although even in these the nuclear phenomena have not been yet investigated. Whether it may not be found after all that the Ascomycetes are a polyphyletic group is still an open question, but at present, as heretofore, the evidence seems rather to point the other way. For the formation of sub-groups and the determination of their relationships the cell-structures of such forms as Eurotium, Xylaria, Claviceps, Pleospora, \&c., in addition to those 
already known, must be thoroughly investigated and compared.

The motive to such investigations lies, however, not so much in the desire to further pile up evidence on the question of the sexuality of the initial cells of the different ascus-fruits as in the hope that thereby further light may be thrown on the more general questions as to the structure and functions of the cell. The peculiar types of cell-division, fertilization, \&c., found in the group may be expected to afford useful data for the solution of general physiological problems. One of the most interesting features in the reproduction of Pyronema is the fact that we have in it a case of the fusion of multinucleated sexual cells. The hyphal cells of Pyronema are regularly multinucleate, and, as has been shown, the oogonia and antheridia contain a large and variable number of nuclei at all stages in their development. In the fusion of these cells the nuclei fuse in pairs so that the general result, so far as the nuclei are concerned, does not differ from what is found in sexual fusions ordinarily.

An interesting question arises, however, as to the nature of such multinucleated sexual cells. Is the oogonium for instance to be regarded as a mass of oogonia whose cell walls have been obliterated or have never existed, or is it to be regarded as a single cell ? Is a 'coenocyte' a cell or a tissue? It is not merely a question of names, since from both the morphological and physiological standpoints our conceptions of the cell and of the tissue differ very widely, and it is worth while to determine, if possible, which of these types the 'coenocyte' resembles more nearly. The suggestion of the energide doctrine by Sachs has been taken up uncritically and carried too far by many. The cell is not necessarily a uninucleated mass of protoplasm. Whether the conception of the cell should be so extended as to include such differentiated structures as Caulerpa and Bryopsis is perhaps not so plain. Still the difficulties involved in regarding them as cells are not due to the fact that they are multinucleated. The differentiation shown by these plants is in the cytoplasm and 


\section{Harper.-Sexual Reproduction in Pyronema}

not, so far as we know, in the nuclei, which are all at least potentially equivalent in their capacity to transmit the hereditary characters of the organism or to influence the metabolism, since so far as known any of these nuclei may be used to form a reproductive spore, and by the streaming of the cytoplasm they are carried successively to rhizoid, stem, and leaf.

These organisms would be quite as difficult to include in the category of cells, if they were uninucleate, if that were conceivable. They represent the extremes of differentiation yet discovered in a structure enclosed by a common cell wall and plasma-membrane, but it is quite as difficult to consider them from the standpoint of tissues since in their metabolism and irritability, they are by no means compounds made up of equal and co-ordinate units. On the whole it does less violence to the facts to class them as cells than in any other category yet proposed. There is nothing in our conception of a cell that is negatived by the assumption of the differentiation of its parts into organs of nutrition, organs for attachment, reproduction, \&c.

In the case of all such multinucleated cells as are combined in filaments or other structures the interpretation is much easier. The red Algae afford exceedingly interesting evidence against the possibility of separating uninucleated from multinucleated cells, since in immediate connexion with each other in the same thallus we have vegetative cells that are regularly uninucleated, and others that are just as regularly multinucleated. It is plainly doing violence to the most obvious relationships to call the one type a cell and the other a tissue.

The multinucleated vegetative cells and sexual cells of Pyronema fall in this same class, and if we compare in detail these coenocytic cells with uninucleated cells and with tissues composed of the latter, it will be seen that the coenocyte is a single cell in all its essential properties and not a compound. Anatomically and morphologically the cell is a mass of protoplasm enclosed by a continuous semi-permeable and 
irritable membrane, and from this standpoint it may be one- or many-nucleated. That there is a certain unity in a mass of tissue such as a palisade parenchyma made up of cells combined in a leaf for the performance of a definite function is not to be questioned, but this unity is achieved by the combination of the activities of a number of independent co-ordinate individuals. Each cell in the tissue receives its own nutrition and throws off its own wastes, and each receives and reacts to stimuli from its environment.

The continuous plasma-membrane enclosing a coenocyte is plainly in its relation to the other cell-contents to be compared with the same structure in a uninucleated cell rather than with the aggregate of membranes, which bound off a mass of tissue from its environment, and the cells of the tissue from each other. And it is this bounding layer which through its properties as a semi-permeable membrane regulates the income and outgo and thus the nutrition of the cell, and also, according to Noll (26) at least, determines its reactions to external stimuli.

The sum of the reactions in a mass of tissue-cells may be in harmony and serve some common end for the organism, but they are none the less independent in origin and in their accomplishment in that they are co-ordinated. In the case of a multinucleated cell we have no evidence that either the process of taking in food or the reception of stimuli is in anything different from what it is in the case of a uninucleated cell-except perhaps in the amount of food taken in-the multinucleated cell being frequently proportionally larger.

The motions of a multinucleated plasmodium compared with those of a uninucleated amoeba show no indication of being compounded from the motions of independent units. So far as can be judged from its amoeboid and streaming movements the plasmodium is a unit in the same sense as is the amoeba.

Schenk (30) has presented evidence that the katabolic processes by which energy is liberated are functions of protoplasm independently of its organization into cells, and that 
similarly contractility and irritability are manifested by protoplasm independently of the aggregation of its parts in cells. A bit of an amoeba cut off from the parent cell and not containing any portion of nuclear material still responds to stimuli, is contractile, and creeps about in apparently normal fashion. It must be concluded that the liberation of energy for motion and the response to external stimuli is independent of any interrelation between nucleus and cytoplasm, and in the manifestation of all such phenomena the uninucleated and multinucleated cells would be at least on an equal footing.

The uninucleated swarm-spore of Oedogonium acts no more as a unit in its reactions to light than does the multinucleated swarm-spore of Vaucheria. So far as we know the pollentube with its vegetative nucleus responds to chemical stimuli just as does the multinucleated hypha of Mucor. The uninucleated conidiophore of Basidiobolus orients itself with reference to light-stimuli just as does the multinucleated sporangiophore of Pilobolus.

The metabolism inside the cell in that phase in which food is changed into organized material is doubtless dependent, as Schenk points out, on the interaction of nucleus and cytoplasm. The metabolism of the multinucleated cell is probably carried on in connexion with many centres instead of a single one, but in this respect the conditions here would not be strikingly different from what they are in such cells as are found in the spinning-glands of insects in which the single nucleus is branched so as to extend into all parts of the cell interior (24). These lining elements of spinning-glands cannot certainly be excluded from the category of cells, and, so far as the relations of their internal metabolism to their nuclei are concerned, they cannot be very different from multinucleated cell structures.

The statement has often been made that the Vaucheria filament is a mass of cells which merely lack their partitionwalls. There is, however, no evidence that the reception of food in Vaucheria, its distribution to various parts of the 
filament, and use in furnishing energy for carrying out heliotropic reactions and building cell walls is any different than the corresponding processes in a pollen-tube or a uninucleated cell of Spirogyra. It is probable, as noted above, that the nuclei are centres for the internal metabolism of the cell, but there is no evidence that they influence its absorption of foodmaterials by osmosis and its excretion of wastes any differently in the uninucleated than in the multinucleated condition. It is quite conceivable that any cell of the leaf-mesophyll should perform all its starch-building functions in entire independence of its neighbours, even to the extent of consuming its own product and excreting the wastes, but we cannot conceive any particular uninucleated area (energide) in a Vaucheria filament acting in such perfect independence of neighbouring areas, simply because in the latter case the uninucleated area is not an osmotic unit, but only a part of a larger osmotic system bounded by a single plasma-membrane. The mesophyll-cell in these respects is comparable to the entire Vaucheria filament.

In Volvox the income and outgo can be considered for each individual of the colony separately, and can vary in each according to the individual peculiarities of the cells, while for the so-called energides of Botrydium no such conception is possible. The income and outgo of the whole mass is regulated by a common plasma-membrane. Even assuming that the strands of protoplasm which extend between the neighbouring cells in many tissues really represent continuity and not merely contact of the protoplasm of the respective cells, the case would not be materially altered, since the extreme tenuousness of such strands in most cases would prevent their serving as channels for any rapid interchange of food-materials, as has been pointed out by Pfeffer (28).

Further, the processes of nuclear and cell-division are independent of each other as is most clearly shown in Cladophora, for the lower plants, and in certain types of endospermformation in the Phanerogams. From this standpoint we can still further sharpen our distinction between cells and tissues 


\section{Harper.-Sexual Reproduction in Pyronema}

by noting that it is only the division of the cell-body as a whole which leads to tissue-formation. Nuclear division may occur without cell-division and consequent tissueformation, and in the case of sporangia, asci, \&c., nuclear division may be followed by cell-division without tissueformation. Nuclear division without cell-division gives opportunity for growth of the cell-body but is not tissueformation.

In reproduction the relations are perhaps not so clear. Multinucleated cells reproduce by much the same type of division in Cladophora as do uninucleated cells in the conidiophores of Erysiphe. For sexual reproduction multinucleated cells may return to the uninucleated condition as is presumably the case in the motile gametes of Botrydium and Acetabularia. But that this return to the uninucleated condition is not necessary for sexual reproduction is shown by the case of Pyronema.

In this connexion it is interesting to note that Stevens (33) has recently described the fertilization in Albugo (Cystopus) Bliti as consisting in the fusion of multinucleated sex-cells. His account is entirely opposed to the results obtained by Wager (39) and Berlese (3) on other species of the same or closely related genera. If it is true that we have multinuclear fusions in the sexual cells of one species, and fusion of a single pair of sexual nuclei in those of another, it is further evidence of the close similarity between uninucleated and multinucleated cells. Stevens seems to take the view that his oospheres and antheridia are the equivalents of tissues, since he designates them respectively as compound oospheres and compound antheridia as compared with uninucleated cells with the same function. He does not, however, discuss the question specifically, and his use of the term compound is not entirely clear in this connexion. For example, he does not call attention to the multinucleated conidia of the Albugo as compound conidia, though from analogy he might be expected to do so.

In asexual reproduction by swarm-spores we have both types of cells; for example, uninucleated swarm-spores in 
Oedogonium and multinucleated swarm-spores in Vaucheria As asexual reproductive bodies there is no reason for putting the swarm-spores of Oedogonium and Vaucheria in separate categories so far as their function is concerned.

In the sexual reproduction of Pyronema, however, we have a combination of conditions in that the cells first fuse as individual units, and the nuclei then also fuse in pairs. The oogonium and the antheridium act as units in accomplishing the union and fusion of their respective protoplasmic bodies. There is a single receptive spot at the end of the trichogyne which functions for the entire contents of the oogonium. The oogonium of Pyronema in this respect is to be compared directly with the oogonium of Oedogonium. In the attraction which leads to the fusion of the antheridium and conjugating tube both organs may play a part, but they certainly act in this case in a fashion not to be distinguished so far as their nuclear content is concerned from that which brings together the conjugating tubes from the uninucleated cells of Spirogyra. The fact that there is no rounding up of an oosphere in the oogonium of Pyronema is plainly a secondary phenomenon. In the growth and metabolic processes leading to the differentiation of these cells as sexual organs, there is nothing to distinguish them from uninucleated eggs or sperm-cells. In the nuclear fusions, however, the nuclei, with perhaps a trace of cytoplasm for each, are the units which unite in pairs.

This apparent return in so fundamental a process as sexual fusion to a condition in which the single nuclei act independently may suggest that the original primitive cell was uninucleated. The condition of the multinucleated protoplasmic mass as found in the Siphoneae, for example, would then be regarded as a later modified development. If, however, as has been maintained by several authors ${ }^{1}$, the chromatin is distributed in the form of granules in the cell of a blue-green Alga, this fact must be regarded as evidence that the multinucleated cell may represent quite as primitive a condition as does the uninucleated cell. The behaviour of

\footnotetext{
1 See Fischer, Cyanophyceen und Bacterien, p. 35. Jena, I897.
} 


\section{Harper.-Sexual Reproduction in Pyronema}

the nuclei in multinucleated gametes is not to be regarded as conclusive evidence on this point, even if it bears at all upon it. It is merely a proof that the nuclei are the structures especially entrusted with the function of sexual reproduction, and certainly is not good ground for deciding that multinucleated protoplasmic masses are to be considered as tissues rather than cells. We must rather enlarge our conception of the cell from the morphological standpoint to include all protoplasmic masses enclosed by a continuous plasma-membrane. Physiologically it is the unit in nutrition, growth, irritability, and asexual reproduction, whether one- or manynucleated. In sexual reproduction, on the other hand, the function of transmitting hereditary characters is probably to be attributed largely to the nucleus as an independent organ.

The significance of multinucleated cells in the plant-economy is doubtless different under different conditions. After the cell has reached a certain size further growth makes distribution of the nuclear material desirable in order that the nuclear activities may be represented equally in all its parts. In the hyphae of Sphaerotheca, on the other hand, whose cells contain one to several nuclei, this inequality and the multinucleated condition itself may be merely the result of the fact that a perfect correlation between the processes of nuclear and cell-division has not yet been attained.

In the sexual cells of Pyronema, as I have described them above, the multinucleated condition is plainly an advantage in insuring the simultaneous fertilization of large numbers of nuclei, and in the motility which is thus secured for relatively large masses of protoplasm. If the oogonium, for example, were uninucleated, a period of nuclear division would have to be interposed between fertilization and ascospore formation which is probably a much less favourable time for such processes than that prior to fertilization, when the numerous nuclei of the oogonium, as we have it, are produced. The conditions in Pyronema as compared with those in Nemalion, for example, may be regarded as intended to transfer the work of producing the numerous nuclei to be used in spore- 
production from the period after, to that just preceding fertilization.

If we attempt to compare the sexual organs and the ascus-fruit of Pyronema with the reproductive organs in other Fungi and Algae, the fundamental resemblance in the process here to what we find in the Lichens as described by Stahl and other authors noted above, is at once apparent. De Bary (13) has already discussed this resemblance fully but without a knowledge of the behaviour of the contents of the sexual cells in the fertilization of Pyronema. The fact that the basal wall of the conjugating tube is broken down for fertilization strengthens the resemblance between this organ and the trichogyne of the Lichens. To be sure, the actual fertilization has not yet been observed in any Lichen, still the morphological significance of the organs concerned is established beyond question. That the trichogyne should be a multicellular hypha is remarkable; but the fact that the entire mass of antheridial nuclei does migrate through a connecting tube to the oogonium in the case of Pyronema, makes it less difficult to assume the correctness of Stahl's interpretation of the structures in the Lichens. The fertilization in the Lichens consists presumably in the fusion of a single pair of sexual nuclei, but this cannot affect the question of the homology of the parts as I think I have shown above.

The resemblance between Pyronema and the red Algae is certainly very striking. The tubular trichogyne which is simply a prolongation of the oogonium of Nemalion or Batrachospermum is strikingly similar to the conjugating tube in Pyronema. Davis (10) has endeavoured to show that the trichogyne of Batrachospermum is a distinct cell. His results are opposed by Schmidle (31) and Osterhout (27) who deny the existence of a nucleus in the trichogyne. But in any case the homologies would not be affected. The trichogyne in Pyronema is an outgrowth of the oogonium, and it would make little difference in its morphological significance whether a cross-wall were put in between the two or not, though the development of this wall is of considerable functional impor- 


\section{Harper.-Sexual Reproduction in Pyronema}

tance. With its one-celled trichogyne Pyronema forms an interesting link between the Florideae, where the trichogyne is a mere beak on the oogonium, and the Lichens, where it is a row of cells.

In the discussion of the question as to whether the tendency to dioecism is a sufficient explanation for the appearance of spermatia in the place of attached antheridial cells, there is little evidence to be added to that presented by De Bary. As to the general similarity of the apothecium of Pyronema and the cystocarp or favella of the red Algae there can be no question. In each we have a fertilized cell which by vegetative growth develops a mass of spores, in the one case ascospores, in the other carpospores. That in the one case the spores are produced by free cell-formation, while in the other they are budded off from the surface of a placental cell or cells does not affect the resemblance so far as its general features are concerned. Whether the vegetative growth of the fertilized cell is to be interpreted as an alternation of generations in either or both cases remains to be settled by a more accurate account of the chromosome-number in the two stages. That there is no oosphere rounded up and set free in an oogonium in either case cannot be regarded as a fact of very fundamental significance. The fertilized egg of the Moss or Liverwort remains in parasitic relationship with the mother plant through its whole development. In Sphaerotheca, for example, we need only consider that the parasitic relationship is more perfect, so that the egg is never set free from actual vegetative union with the parent plant. However the nature of the growth directly from the egg may be interpreted, there is no question that the protective hyphal envelopes developed around the ascogonium and asci are nothing but a further outgrowth of the sexual mycelium comparable to the development of the archegonium and calyptra in the Moss.

After what has been said of the relationship of Pyronema and the red Algae it will be seen at once that the connexion of the former with the Laboulbeniaceae must be both inter- 
esting and suggestive. Thaxter (34, p. 253) considers that the Laboulbeniaceae may stand between Sphaerotheca and the red Algae. Pyronema, in the character of its trichogyne, stands closer to the red Algae than do the Laboulbeniaceae, but in its attached antheridial cell it is more like Sphaerotheca. Thaxter $(34$, p. 225) has described a very interesting series of modifications in the development of the trichogyne in the Laboulbeniaceae. In Stigmatomyces it is a single, onenucleated cell without branches. In Peyritschiella, Amorphomyces, and other genera, the one-celled trichogyne has branches shorter or longer, and more or less numerous. Other forms have multicellular trichogynes which may be simple or very abundantly branched (Teratomyces). The extremities may be spirally twisted as in Compsomyces. In all cases the trichogyne is borne upon a special trichophoric cell which is thus interposed between it and the carpogonium which is to be fertilized. The conjugating apparatus is seen thus to consist of two independent cells in the simplest Laboulbeniaceae as compared with one cell in Pyronema (the trichogyne), and a simple tubular prolongation of the egg-cell in the red Algae such as Nemalion and Batrachospermum. Such forms as Teratomyces with multicellular branching trichogynes represent still more differentiated types in this particular than the Lichens, where it also seems probable that a trichophoric cell is interposed between the carpogonium proper and the trichogyne.

The discovery of these extremely complex multicellular trichogynes of the Laboulbeniaceae, whose function as conjugating organs cannot be questioned, and which are connected by forms of all stages of complexity with the simple onenucleated trichogyne of the Stigmatomyces type, certainly removes all doubt as to the existence of structures which must be considered morphologically as multicellular conjugating tubes. And the account of the breaking down of the walls and the migration of the male nuclei through the trichogyne of Pyronema given above furnishes the positive evidence that such conjugating tubes are the channels through which male pronuclei are conveyed to the egg-nuclei with which they 


\section{Harper.-Sexual Reproduction in Pyronema}

are to fuse. The Lichen trichogyne is made up of many cells, while that of Pyronema is a single cell, but if two walls can be broken down to permit the passage of the male nuclei there is no reason why a larger number may not be. Under conditions which necessitate a longer trichogyne such as we find in the Lichens it is entirely natural that it should be a multicellular rather than a unicellular structure.

Arranged according to the degree of complexity of the trichogyne we should have a series as follows: Batrachospermum with the trichogyne a mere tubular outgrowth of the oogonium, Pyronema with this tubular outgrowth cut off by a septum so as to form a cell, Stigmatomyces with a second cell cut off as a trichophore at the base of the trichogyne, and Collema and other Lichens with the trichogyne divided by further septa into a row of cells, while the branched multicellular trichogynes of Teratomyces and Compsomyces afford examples of still greater complexity of development in this organ.

Such a series of course cannot be regarded as showing the relationships of the different forms in the order indicated. It merely shows the possibility of such a series of forms having existed in the ancestry of the Lichen, and thus does away to a large degree with the difficulty which has been felt over the conception that such a multicellular hypha as the Lichen trichogyne could serve as a conjugating organ.

Thaxter has made the very interesting observation that in some cases the trichogyne grows down at first toward the antheridium so as to seek out as it were the non-motile male cell and thus insure fertilization. In the genus Zoidiomyces the trichogyne grows down at first and receives the antherozoid on its tip when it turns and grows upward again into its apparently more normal position. This reversal of the ordinary relations of the sexes in the act of fertilization in which the egg-cell supplies an organ for seeking out the male cell is exactly what was observed to a less degree by Tulasne in Pyronema. The egg thus ceases to be a merely passive receptive cell when it has developed a trichogyne. And it 
may be that the increased certainty of fertilization assured in this fashion is the condition which has enabled the plants possessed of trichogynes to dispense with motility in their male cells.

While it may be regarded as established that the general similarity between the sexual reproduction in the Ascomycetes and the red Algae as pointed out by De Bary (12, pp. 86-88) exists, still in my opinion it is of no special value at this time to attempt to establish, from the forms which have been worked out, just how an evolutionary transition may have developed the Ascomycetes from the Algae. More forms must be investigated, and then at best the proof will probably be inconclusive. It is plain that the Ascomycetes resemble the red Algae more than they do the lower Fungi ${ }^{1}$, but whether these resemblances are a result of blood relationship, or are merely due to that similarity in the chemical constitution of the protoplasm of different organisms, which under similar conditions enables it to develop structures nearly related in appearance out of rudiments which may be extremely diverse, is likely to remain a puzzling question.

I have shown elsewhere that there is no sufficient evidence that the sporangium of the Moulds has been evolved into the ascus of the higher Fungi, and that hence any classification which connects the two groups on the basis of an assumed relationship between these structures is purely artificial and formal. On the other hand there is as yet no direct evidence of the transformation of the cystocarp with its carpospores into the ascocarp with its ascospores formed by free cell-formation, and hence the attempt to form a natural classification in which the one group is regarded as representing the source of the other is premature at least. For the present we must be content to allow the Ascomycetes to stand alone, with the hope that the thorough investigation of all the types in the group itself as well as the forms of

1 De Bary's (12, pp. 109-I19) view of the relationship of Sphaerotheca to the Peronosporeae was based on a want of knowledge of the structure of the mature ascogonium in the former and need not be further discussed.

D d 2 


\section{Harper.-Sexual Reproduction in Pyronema}

doubtful relationship to the main series may bring further evidence as to its phylogeny.

If we turn now to problems of relationship inside the group itself, and compare the sexual apparatus as we find it in Pyronema and Sphaerotheca, we are confronted by some marked differences in detail. A conjugation-tube or trichogyne is entirely wanting in Sphaerotheca. A further difference lies in the fact that in Pyronema the oogonium functions without further growth as an ascogonium. All the fertilized nuclei pass into ascogenous hyphae and may reach the asci, while in Sphaerotheca the single fertilized egg develops a row of cells of which only one becomes an ascus, while the others. undergo degeneration. There is nothing in Pyronema to correspond to this growth of an ascogonium from the fertilized egg, and in this respect it seems to represent a simpler condition than Sphaerotheca. Also the fact that the entire protoplasmic mass of the oogonium, except in the case of unfertilized nuclei noted above, passes out into the ascogenous hyphae seems perhaps to indicate a simpler condition. It is perhaps analogous to the setting free of the egg-protoplasm from the oogonial cell wall which we find in those oogonia which produce regularly one or more free oospheres in their interior.

It is possible again that the ascogonium in Sphaerotheca and Erysiphe is in reality comparable to a single ascogenous hypha in Pyronema, in which case the two types could be conceived as more nearly related. Such comparisons, however, may very well be deceptive, since it has been shown many times that resemblance in form may be found where no genetic relationship between the parts or organisms compared can be assumed.

So far, however, as the trichogyne is concerned, we can readily imagine the development of the type in Sphaerotheca into that in Pyronema. The oogonium would need only to develop a conjugating beak such as is seen in Coleochaete, and this could be readily conceived as gaining final differentiation as a cell by the putting in of the partition- 
wall at its base. Such a change as this would be a very natural correlation of the multinucleated condition and consequent enlargement of the antheridial cell which we find in Pyronema. It is to be remembered that the long club-shaped antheridium of the latter is to be compared with the antheridial cell of Sphaerotheca, not with the entire male branch of the latter. It is easy to see that a cell containing the mass of nuclei present in the antheridium of Pyronema could hardly be perched upon the apex of the oogonium as is the small antheridial cell of Sphaerotheca. We can readily conceive, then, the development of the conjugating tube as a means of overcoming this difficulty. Still I am inclined to believe that in reality the reverse process has taken place, and that the sexual apparatus with the trichogyne represents the more primitive type for the Ascomycetes.

Sphaerotheca and the Erysipheae, as I have already pointed out, may well be considered as a highly specialized group because of their parasitic habit and haustoria and their complex appendages, as compared with the relatively simple secondary mycelia of Ascobolus and Pyronema.

In view of the difference between the sexual apparatus in the Erysipheae and that in Pyronema, it is very interesting to note that Ascobolus, in the structure of its fully developed ascogonium, while superficially it is more like Sphaerotheca than Pyronema in one most important feature, is much more closely related to the latter. While in Sphaerotheca and Erysiphe only one cell of the ascogonium has its contents utilized in the formation of asci, the entire contents of the ascogonium of Ascobolus are emptied by means of the pores in its septa into the cell from which the ascogenous hyphae spring, and thus are utilized in ascus-formation. Similarly, as we have seen above, the entire contents of the ascogonium of Pyronema are utilized in ascus-formation. In view of these facts it would be extremely interesting to know exactly the nature of the earliest stages in the development of the ascogonium in Ascobolus.

In the Laboulbeniaceae, as Thaxter shows (34), this differ- 
entiation of the product of the egg has taken place in all cases. The carpogonium regularly divides into three cells, of which only the central one produces asci; and in some cases this central cell cuts off a so-called secondary stalk before proceeding to the development of asci. In the red Algae, too, the egg regularly produces a certain amount of sterile tissue in addition to the carpospores, so that from this standpoint the problem of the relationships of the various forms becomes a very complicated one.

Further, Eurotium, as described by De Bary, shows a very close relationship to Pyronema in the structure of the sexual apparatus (12), and also an interesting resemblance to the Lichens. Indeed, Eurotium forms a very good intermediate type between Pyronema and the Lichens in many respects. In it we have a coiled female branch made up of several cells, the upper one of which conjugates with an antheridial cell. This upper cell of the coil may well correspond in some fashion to the conjugating tube or trichogyne of Pyronema. The remainder of the coil consisting of several cells serves as the origin for the ascogenous hyphae, being in this respect similar to the ascogonium of the Lichen type. How the fertilization is accomplished in this case, whether there is a migration of a nucleus or nuclei through the apical cell to the cells below as in Pyronema, or whether the lower cells serve as auxiliary cells like those in certain red Algae as described by Oltmanns, and as Darbishire thinks is the case in Physcia, must be determined by further investigation.

On the whole it is quite certain that we have as yet no final evidence as to the relationships inside the group of the Ascomycetes. In spite of the vast amount of work which has been done, the number of forms which have been fully described in all their stages, even from the standpoint of their external morphology, is surprisingly small as compared with the number which are yet to be worked out. This is due chiefly to the extreme difficulty experienced in finding the earliest stages in the development of the fruits, which at this time are generally buried in the nutrient substratum, and 
show no evidence of their existence till they burst through the enveloping medium in an advanced stage of development. When we further consider that the coenocytic condition is very common, and that the function of the cells can only be determined through a knowledge of the behaviour of their nuclei, which are frequently minute in size, it is easy to see why our knowledge has not progressed more rapidly.

In this state of affairs it is certainly scientific as far as possible to withhold judgement as to questions of relationship, and above all to refrain from the attempt to force little-known forms together into artificial groups based on mere superficial resemblances. For the present the question as to the relation of Pyronema to the Erysipheae should be regarded as awaiting for its solution a further knowledge of such forms at least as are most closely related to these types, the remainder of the Perisporieae on the one hand and the simpler Discomycetes on the other. It is, however, sufficiently evident that the differences between Pyronema, Sphaerotheca, and the Lichens, cannot be considered as affording sufficient reason for regarding the Ascomycetes as a polyphyletic group. The ascus with its peculiar method of free cell-formation which has not been observed elsewhere as yet among Algae or Fungi is strong evidence for the morphological unity of the group.

Assuming that the ascocarp is always as it has been shown to be in the cases cited, the asexual spore-fruit, developed from a fertilized or possibly in some cases a parthenogenetic egg and its envelopes, the question as to the nature and relationships of the group of the Exoasci seems a difficult one. It would be very interesting to know, in this connexion, how nearly the method of spore-formation in this group corresponds to the method of free cell-formation as I have found it in the Erysipheae and Discomycetes. I have myself begun some studies looking to this end, which are not yet concluded.

As to the morphology and relationships of the group as a whole it is known that Brefeld regards them as very simple forms in which the asci have not come to be enveloped in more or less closed envelopes. Dangeard (7) describes the 


\section{Harper.-Sexual Reproduction in Pyronema}

nuclear phenomena in the young ascus as the same in general as in other asci and considers that the asci here as in other cases are oogonia. He finds, however, no such bending of an ascogenous hypha tip and growth of the ascus from its penultimate cell as is seen in the Discomycetes.

De Bary $(13$, p. 210$)$ puts the group among the doubtful Ascomycetes, and believes they must be regarded as greatly reduced forms, their only relationship with other Ascomycetes being in their hymenia and asci. This latter view seems not improbable, and it seems quite possible to homologize them with certain stages in the development of the Discomycetes. I have already described the relatively independent growth of the ascogenous hyphae in the sub-hymenial layer of such forms as produce relatively large fruit-bodies like Ascobolus furfuraceus. In forms with still larger fruit-bodies such as Peziza Stevensonia, and in numbers of other Pezizas I have examined, this condition is still more striking. The connexion of the sub-hymenial ascogenous hyphae with the ascogonium in Ascobolus disappears at quite an early stage. Indeed the ascogenous hyphae seem never to be nourished by material brought up from the mycelium through the ascogonium, but as far as they obtain new food at all to be dependent on the vegetative hyphae among which they grow. They are parasites on the tissues of the mother-plant just as the sporogonium in the Liverworts and Mosses is parasitic on the gametophyte generation. If now these ascogenous hyphae be transferred to some foreign host-plant they might be imagined as continuing their development indefinitely in the tissues of the host, producing crops of asci continuously or intermittently with periods of rest, \&c. That is, they might develop quite as does the mycelium of such forms as Exoascus aureus on the poplar for example. The mycelium of the Exoasci would, according to this view, correspond to the ascogenous hyphae of the Ascomycetes and not to their ordinary vegetative mycelia. Sexual reproduction might then only occur at long intervals or be entirely suppressed. The ascospores, or the conidia produced from them, might 
further come to germinate directly into ascogenous hyphae by a process of apogamy and the suppression of the ordinary mycelium and sexual organs. The condition would then be physiologically analogous to that in those Flowering Plants such as Allium and Funkia, as described by Strasburger, in which the nucellus-cells, which are potentially spores or spore mother-cells, bud out, push into the embryo-sac, and produce new sporophyte-embryos there in place of the fertilized egg which would normally be developed.

Such suppression of stages in the development of an organism is shown in less degree by the cases of apospory in the Ferns, and the development of new gametophytes from protonemata grown from the vegetative cells of the sporophyte in Mosses, as described by Pringsheim. On the supposition given, the condition in the Exoasci would be quite analogous to what is found in the Rusts according to Raciborski (29), who believes that the original vegetative body in these plants has been almost entirely suppressed, the present mycelium and spore-forms of the group being merely stages intercalated between two phases of the reproductive act, namely, cellfusion and nuclear-fusion. If the fusions of cells and nuclei in the sexual apparatus, and the fusions of nuclei in the ascus should be found to be two phases of a single sexual act, the suppressed stage in the Exoasci on the view suggested above would be the same as that which Raciborski believes has been suppressed in the Uredineae.

The Exoasci certainly give evidence of considerable specialization in their parasitic habit and in their production of conidia in the ascus, and it seems quite as natural from this standpoint to regard them as a specialized offshoot from the main series of Ascomycetes as to regard them as primitive ancestral forms. The fact that their hymenia are without paraphyses is a minor point which agrees well with the hypothesis I have advanced above, since in the typical Ascomycetes paraphyses are outgrowths of the vegetative mycelia and not of the ascogenous hyphae.

Whether or not this is the true explanation of the reduced 
condition of the Exoasci it is at least apparent that the absence of sexual apparatus in them cannot be regarded as evidence of the absence of sexuality in other more typical Ascomycetes. De Bary's view that they are reduced and specialized forms is at least as well founded as the view that they are typical of the primitive Ascomycetes. Dangeard's (7) view also, according to which the Exoasci furnish evidence of the sexual nature of the nuclear fusions in the ascus, cannot be regarded as conclusive, since I have shown that similar nuclear fusions occur in asci arising themselves from a fertilized egg in the Erysipheae and Pyronema. Until the method of spore-formation in the group has been worked out the question as to its position and relationships may be left entirely open.

The significance of these nuclear fusions in the ascus is very obscure. Still the entire process in sexual cells and asci is not without analogy elsewhere. Chmielewski (6) has described the nuclear phenomena in the zygospore of Spirogyra as consisting of a nuclear fusion at the time of cell-conjugation followed by a double division of the fusion-nucleus, the disappearance of one pair of nuclei so produced, and the fusion of the other pair. Wager (40) has pointed out that this process seems somewhat similar to the series of nuclear phenomena in Sphaerotheca. The fertilization occurring in the oogonium would correspond to the first fusion in Spirogyra. The period of growth of the ascogonium is then interpolated, followed by a second fusion in the ascus corresponding to the second fusion in the zygospore. In Pyronema the same comparison can be made, and further, the disintegration of the two nuclei in Spirogyra may be analogous to the cutting off of the two nuclei at least in some cases in the sterile cells at each side of the ascus-bearing cell; but here again the apparent resemblance may have more or less morphological significance.

We certainly need more light on the phenomena of chromosome-reduction, and the method and time of its occurrence in the lower plants, before a conclusion can be reached on this 
point. The number of chromosomes must be first determined in both vegetative and reproductive cells at all stages. As a contribution in this line I have attempted to count the visible number of chromosomes on the spindles in a large series of nuclei in the divisions in the ascogenous hyphae just prior to ascus-formation, and also in the asci themselves. The figures are so small and the chromosomes so crowded that it is extremely difficult to get satisfactory results. The chromosomes overlap and are bunched in many cases so that neither polar nor side views reveal the exact number with certainty. The larger nuclei in the first division in the ascus are by far the most favourable for this work, and I am of the opinion from a study of a large series of cases that there are ten chromosomes present at this stage. In Peziza Stevensoniana I was able to determine that their number is not changed in the three divisions in the ascus, and I am of the opinion that the same is true for Pyronema, though the smaller size of the nuclei in the second and third divisions here makes them much less favourable objects of study.

As to the number of chromosomes shown in the division in the ascogenous hyphae I am uncertain. As is seen from Figs. $25-28$ the visible number of chromatin granules on the spindle is variable. This is doubtless due to massing of the individual chromosomes in some cases and to the fact that they may lie vertically above one another in the spindle. It is also difficult to determine in many cases whether the separation of the daughter-chromosomes in the equatorial plate has taken place. Polar views do not seem much more favourable for determining the number than do side views of the spindle as will be seen from the upper nuclei in Figs. 27 and 28. All the Figs. $25^{-28}$ have been drawn with great care to show exactly the number of granules visible in each case. I am inclined to the view that the same number, that is ten, is present here as in the divisions in the ascus described above. Whether this is the double number which results from the fusion in the oogonium, or whether reduction has already taken place is uncertain. I have already pointed 
out the possibility that reduction may occur in the ascus, the threefold division of the ascus-nucleus being possibly homologous with the double divisions of the spore mother-cells in the higher plants; but the simultaneous divisions just prior to the formation of the ascus with the production, in some cases at least, of two nuclei which develop no further, suggest the possibility that reduction may occur at this stage. It is quite possible that the stages in development here are not to be homologized with those in the higher plants where a definite alternation of generations occurs ; still the ascocarp certainly plays the same rôle physiologically as the sporophyte of the higher plants, and the morphological equivalence of the structures concerned is at least strongly suggested. From this standpoint reduction might occur at either of the stages mentioned above. Further study of the chromosome number in various forms among the thallophytes is necessary before a definite conclusion can be reached on this point. 


\section{INDEX OF LITERATURE.}

1. BAur, Erwin: 'Zur Frage nach der Sexualität der Collemaceen. Ber. d. deutsch. Bot. Gesell., Jahrg. I898, p. $3^{6} 3$.

2. BAUke: Zur Kenntniss der Pykniden. Nova Acta, xxxviii, ז876. Zur Entwickelungsgeschichte der Ascomyceten. Bot. Zeit., I877.

3. Berlese : Über die Befruchtung und Entwickelung der Oosphäre bei den Peronosporeen. Jahrb. f. wiss. Bot., Bd. xxxi, p. I59.

4. Brefeld and Möller: Über die Cultur flechtenbildender Ascomyceten. Münster, I887.

5. Brefeld : Bot. Untersuchungen über Hefenpilze, Heft v, pp. 33, 49, 50, I 75 .

6. Chmielewski : Referat in Bot. Centralbl., Bd. 1, i892, p. 264.

7. Dangeard, P. A. : La Reproduction sexuelle des Ascomycétes. Le Botaniste, iv, I 894 , pp. $2 \mathrm{I}-5^{8}$.

8. Dangeard, P. A.: Second Mémoire sur la Reproduction sexuelle des Ascomycétes. Le Bot., ser. v, I897, pp. 245-284.

9. Darbishire, O. V.: Über die Apothecienentwickelung der Flechte Physcia pulverulenta (Schreb.), Nyl. Jahrb. f. wiss. Bot., Bd. xxxiv, p. 329, i 899 .

10. DAvis : The fertilization of Batrachospermum, Ann. of Bot., x, 49, 1896 .

11. DE BARY: Entwickelungsgeschichte der Ascomyceten. Leipzig, r863.

12. De Bary und Woronin : Beitr. zur Morph. und Phys. der Pilze, 3. Reihe. Frankfurt, I870.

13. De BARY: Vergl. Morph., Phys. und Biol. der Pilze, Bact. und Mycetozoa. Leipzig, I884.

14. FüNFStück, M. : Beiträge zur Entwickelungsgeschichte der Lichenen. Jahrb. d. k. botan. Gartens u. Museums z. Berlin. Berlin, I884.

15. Fünfstück, M.: Lichenes, A. Allgemeiner Theil, in Eng. u. Prantl, Die natürlichen Pflanzenfamilien, i, I, I 898.

16. HARPER : Über das Verhalten der Kerne bei der Fruchtentwickelung einiger Ascomyceten, Jahrb. f. wiss. Bot., Bd. xxix, und Kerntheilung u. freie Zellbildung im Ascus, Jahrb. f. wiss. Bot., Bd. xxx.

17. HARPER : Nuclear phenomena in certain stages in the development of the Smuts. Trans. Wis. Acad. of Sci., vol. xii, pp. 475-498. October, 1899 .

18. HarPer: Die Entwick. des Perith. bei Sphaerotheca Castagnei, Ber. d. deutsch. Bot. Ges., Bd. xiii, p. 475.

19. Krhlmann: Zur Entwickelungsgeschichte der Ascomyceten. Acta Soc. Fennicae, xiii, 1883 .

20. KRABBE : Morphologie und Entwickelungsgeschichte der Cladoniaceen. Ber. d. deutsch. Bot. Ges., Feb. I883, und Beitr. z. Kennt. der Ascomyceten, Leipzig, r89 .

21. LindaU, G.: Über die Anlage u. Entwickelung einiger Flechtenapothecien. Flora, I 888 .

22. LindaU, G.: Beiträge zur Kenntniss der Gattung Gyrophora. Festschr. f. Schwendener. Berlin, 1899. 


\section{Harper.- Sexual Reproduction in Pyronema}

23. Loeb, J.: ' Über die Natur des Befruchtungsprocesses und die künstliche Hervorbringung normaler Larven (Plutei) aus den unbefruchteten Eiern des Seeigels,' Am. Jour. of Physiol., vol. iii, p. I35, 1899.

24. Mayer, Paul: See Hertwig, Die Zelle und die Gewebe, p. 33. Jena, I893.

25. Nichols: The morphology and development of certain Pyrenomycetous Fungi, Bot. Gaz., vol. xxii, p. 30r. See also Just's Gahresber., I896, I. Abt., p. 278.

26. Noll: Die Wirkungsweise von Schwerkraft und Licht auf die Gestaltung der Pflanze, Naturwiss. Rundschau, Bd. iii, p. 57.

27. Osterhout : Befruchtung bei Batrachospermum, Flora, Bd. lxxxvii, p. Iog.

28. Pfeffer: Pflanzenphysiologie, 2. Aufl., p. 98.

29. Raciborski et Poirault : Sur les Noyaux des Urédinées. Journal de Bot., $9^{\circ}$ année.

30. Schenk : Physiologische Characteristik der Zelle, viii. Würzburg, I899.

31. Schmidle: Einiges über die Befruchtung, Keimung und Haarinsertion von Batrachospermum, Bot. Zeit., lvii, p. I25, I 899.

32. STAHL: Beiträge zur Entwickelungsgeschichte der Flechten, i. u. ii. Leipzig, 1877 .

33. Stevens, F. L.: The Compound Oosphere of Albugo bliti. Bot. Gazette, September and October, $\mathbf{1} 899$.

34. ThAXTER : Contributions toward a monograph of the Laboulbeniaceae. Mem. Am. Acad. of Arts and Sciences, vol. xii, No. 3, 1895.

35. Tulasne: Selecta fungorum Carpologia. I86I.

36. Note sur les Phénomènes de Copulation que présentent quelques Champignons. Annales des Sciences Naturelles, $5^{\circ}$ sér., tome vi, p. 217 , 1866.

37. Van Tieghem: Traité de Botanique, tome ii, I89I.

38. WAGER: Observations on the structure of the nuclei in Peronospora parasitica and on their behaviour during the formation of the oospore. Ann. of Bot., vol. iv, p. I 27.

39. WAGER : Reproduction and fertilization in Cystopus candidus. Ann. of Bot., I 896 , vol. x, p. 89 .

40. The sexuality of the Fungi. Ann. of Bot., vol. xiii, Dec., 1899 .

41. Wainio, E.: Étude sur la classification naturelle et la morphologie des Lichens du Brésil. Helsingfors, 1890. 
confluens and the Morphology of the Ascocarp. 399

\title{
EXPLANATION OF FIGURES IN PLATES XIX-XXI.
}

\author{
Illustrating Professor Harper's paper on Pyronema confluens.
}

PLATE XIX.

All figures were drawn with the aid of the camera lucida, and with the Zeiss apochromatic objectives. Figs. 3-IO, I2-I 5, I $7 a, 17 b, 19-22$, and 24 with obj. $2 \mathrm{~mm}$. compens. oc. 4 . Fig. I I with obj. $2 \mathrm{~mm}$. oc. 6 . Figs. 2, I6, I6 $a, \mathrm{I} 6 b, 3 \mathrm{I}$, 42 , and 43 with obj. $2 \mathrm{~mm}$. oc. 8 . Figs. $25-30,32-4 \mathrm{I}$ with obj. $2 \mathrm{~mm}$. oc. I 2 . Fig. I 8 with obj. $8 \mathrm{~mm}$. oc. 12 . Fig. 23 with obj. $8 \mathrm{~mm}$. oc. 4 .

Fig. I. Rosette of three pairs of sexual cells drawn from surface view, the group slightly flattened by pressure.

Fig. 2. Branched mycelial cell showing nuclei and granules on the septa.

Fig. 3. Young pair of sexual organs with vegetative cells below. Trichogyne appears as a mere papilla on the oogonium.

Fig. 4. Older pair, trichogyne not yet cut off from oogonium. Antheridium cut transversely.

Fig. 5. Longitudinal section of antheridium. Trichogyne cut obliquely showing smaller nuclei.

Fig. 6. Oogonium and trichogyne cut longitudinally. Oogonium stalk with budding vegetative hyphae. Trichogyne with hyaline beak, its nuclei swollen and transparent.

Fig. 7. Longitudinal section of antheridium; oblique section of trichogyne showing the fusion-pore. Nuclei of antheridium not yet disintegrated as they commonly are at this stage.

Fig $8 b$. Oblique tangential section of antheridium. Trichogyne cut transversely near its base and apex. Pore forming by solution of walls between trichogyne and antheridium. $a$. Remainder of same trichogyne from next section showing disintegrated nuclei.

Fig. 9. Oblique section of antheridium and trichogyne showing receptive spots of each and formation of pore.

Fig. I0. Pore complete and fragments of dissolved wall lying near in the trichogyne. Hypothecial hyphae springing from stalk-cells. Nuclei in trichogyne disintegrated.

Figs. II and I2. Slightly later stage, receptive spots becoming spongy and vacuolar.

Fig. I3. Nuclei beginning to migrate from antheridium to trichogyne. Stalk cut obliquely not showing hypothecial hyphae.

Fig. I4 (Plate XX). Trichogyne filled with nuclei from the antheridium. Nuclei collecting in oogonium. Antheridium curved around the trichogyne so that the latter appears in section to cut through it.

Fig. I 5. Basal wall of trichogyne dissolved and male and female nuclei collected in a dense mass in centre of oogonium and fusing in pairs. Nuclei still present in trichogyne and upper end of antheridium. Ascogenous hyphae appearing as buds on oogonium.

Fig. I $5 a$. Another oogonium at about the same stage as the last. 


\section{Harper.-Sexual Reproduction in Pyronema.}

Figs. $16,16 a$, and $16 b$. Parts of tangential sections of the central mass of nuclei in different oogonia showing groups of fusing nuclei in various stages. $16 a$ slightly less magnified.

\section{PLATE XX.}

Figs. I $7 a$ and $I_{7} b$. Two sections from the same oogonium showing the separation of the nuclei after fertilization. Young ascogenous hyphae containing nuclei. Basal wall of trichogyne again present.

Fig. 18. Approximately horizontal section through a rosette of sexual cells showing distribution of vegetative branches which are to form hypothecium. One of the antheridia does not appear in this section.

Fig. 19. Section of older oogonium showing the distribution of the ascogenous hyphae among the young hyphae of the hypothecium.

Fig. 20. Section of an ascocarp showing, approximately, the hymenium and hypothecium developed from a single pair of sexual cells. $a$. Portion of ascogenous hypha containing unfertilized supernumerary nuclei.

Fig. 2I. Old oogonium with branching trichogyne, which has united with two separate antheridia.

Fig. 22. Oogonium older than that in Fig. 20 and showing large fertilized and smaller unfertilized supernumerary nuclei.

Fig. 23. Semi-diagrammatic drawing of a section of an ascocarp in which the first asci are ripening.

Fig. 24. Storage cells from the hypothecium out of which paraphyses are developed.

Figs. 25,26 . Tips of ascogenous hyphae, from the hymenium, showing pairs of nuclei in division.

\section{PLATE XXI.}

Figs. 27-29. Tips of ascogenous hyphae showing pairs of nuclei in division.

Fig. 30. Tip of ascogenous hypha showing four nuclei formed by the division of the two nuclei shown in preceding figures.

Fig. 3I. Later stage than that in Fig. 30 . Dome-shaped young ascus containing two nuclei. A second ascus forming below.

Fig. 32. Slightly older ascus showing two nuclei and two supporting cells.

Fig. $32 a$. Same stage showing a single supporting cell.

Fig. 33. Nuclei in young ascus fusing.

Fig. 34. Young ascus with single nucleus formed by fusion of the two nuclei shown in preceding stage.

Fig. 35. Primary ascus nucleus in division.

Fig. 36. Two young daughter-nuclei formed by division of primary ascus nucleus.

Fig. 37. Division of the secondary ascus nuclei.

Fig. 38. Dispirem stage of same division.

Fig. 39. Four-nucleated stage in development of ascus.

Fig. 40. Eight-nucleated stage. Nuclei with beaks and asters at the tips of the beaks.

Fig. 4r. Stage in the cutting out of the ascospores by the folding back and fusion of the rays of the aster.

Fig. 42. Young ascospores enclosed only by plasma-membranes.

Fig. 43. Nearly ripe ascospores with fungus-cellulose wall. 

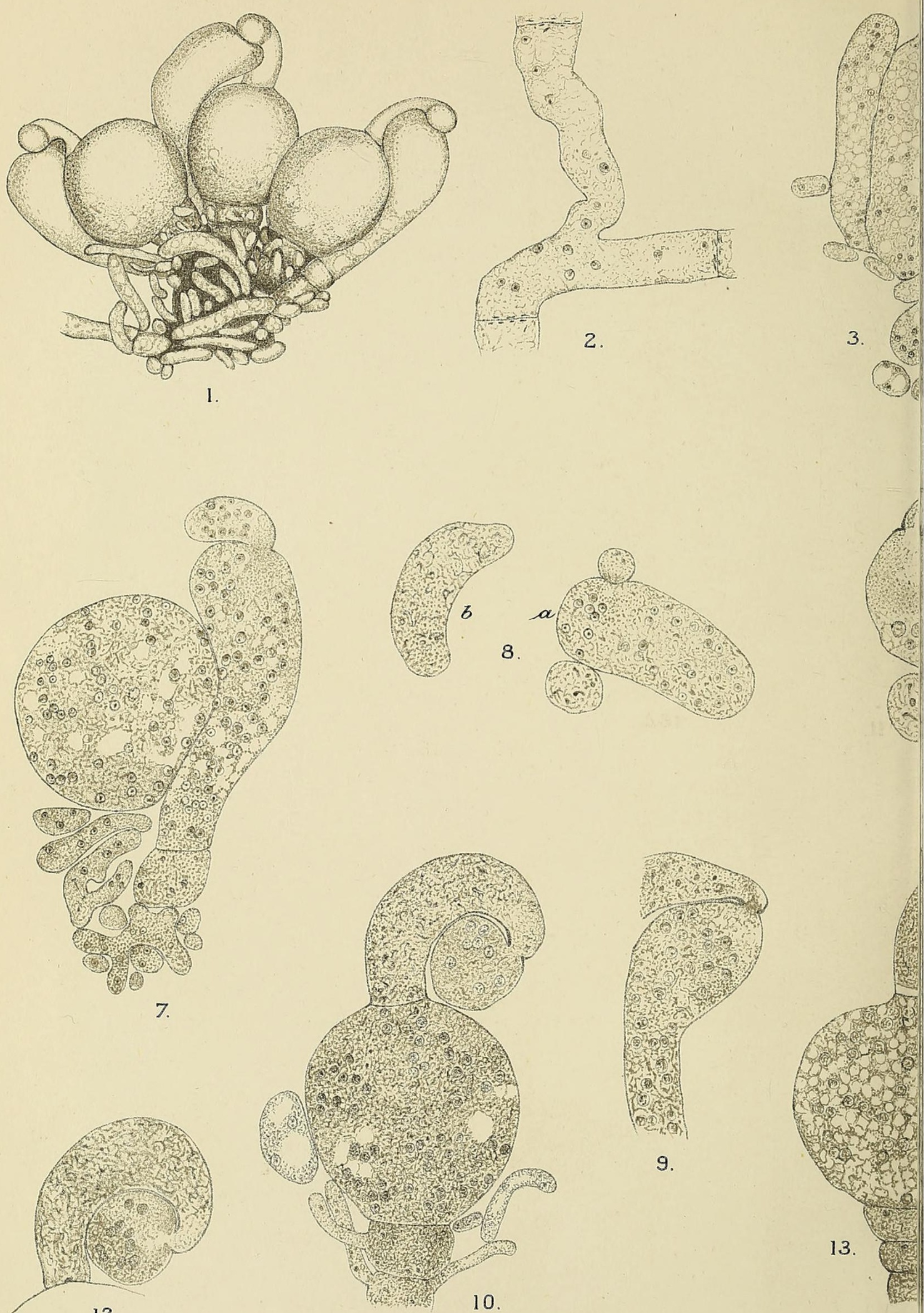

12.

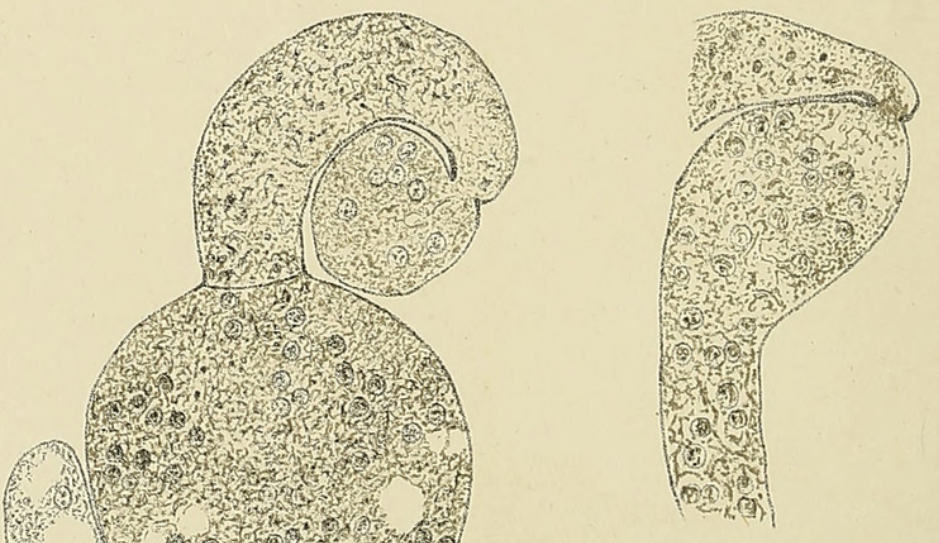

13.

9.

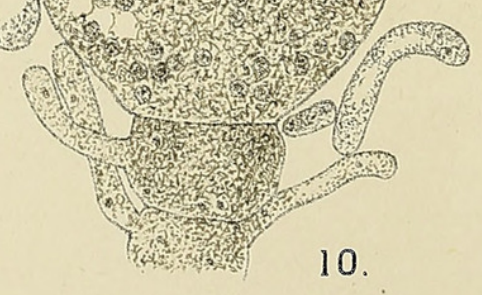



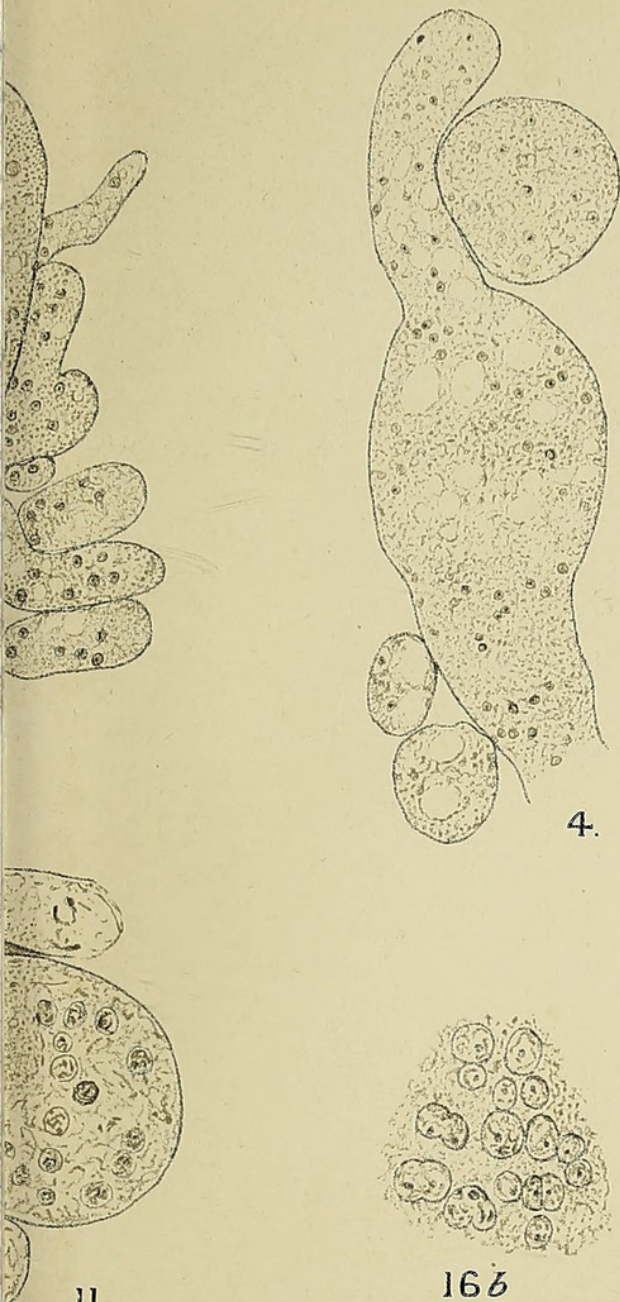

11.

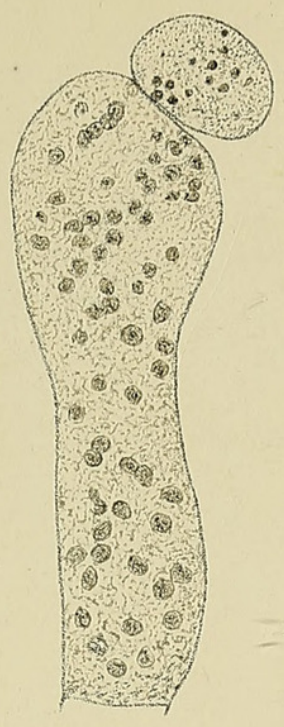

5.

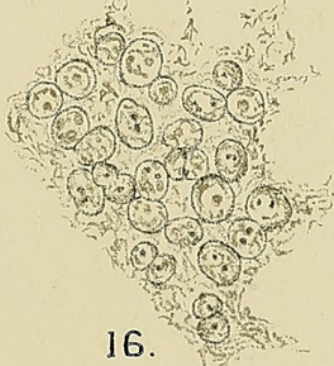

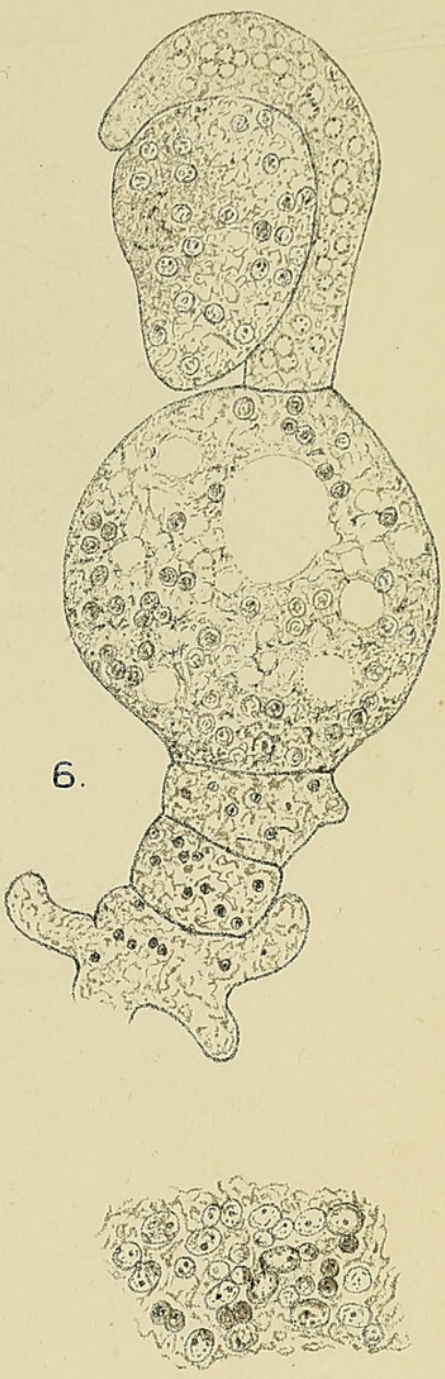

$16 x$
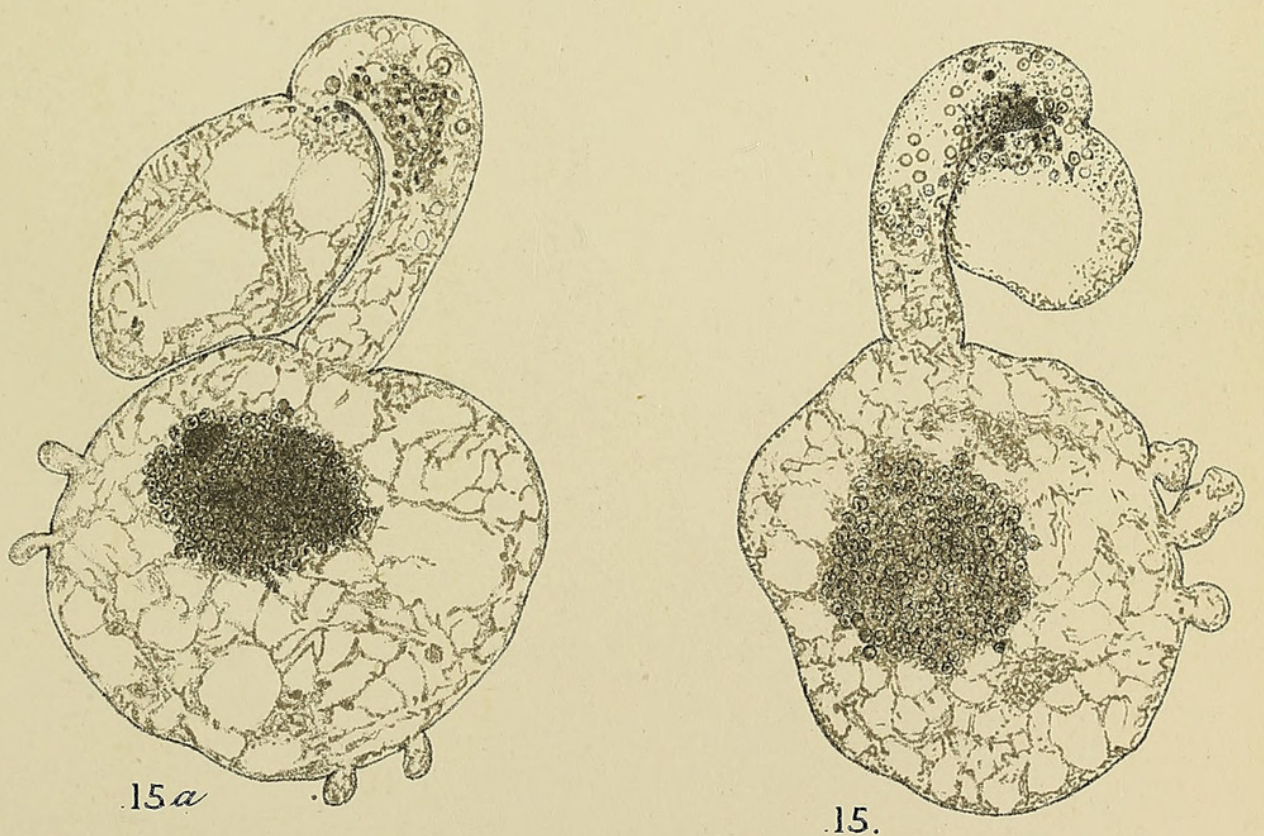

University Press, 0xford. 

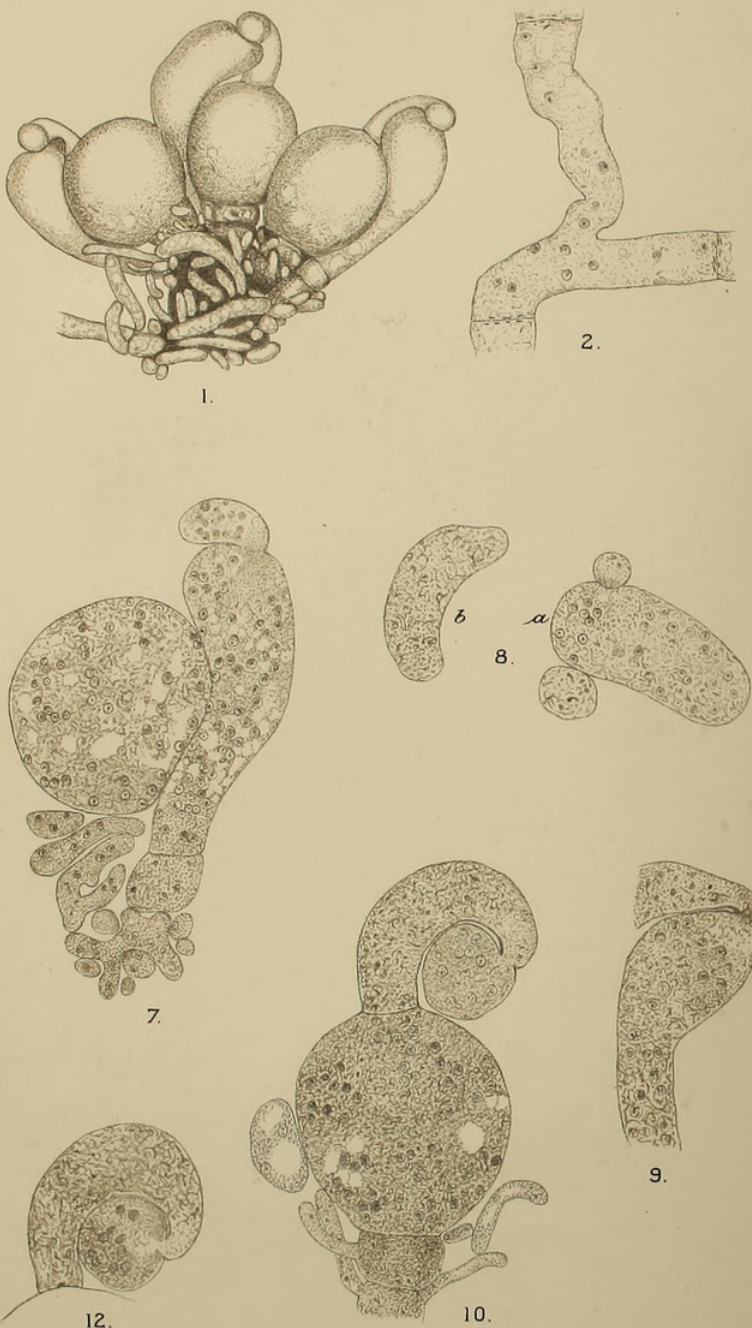

28

$$
\text { if }
$$

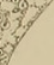

\section{1.}
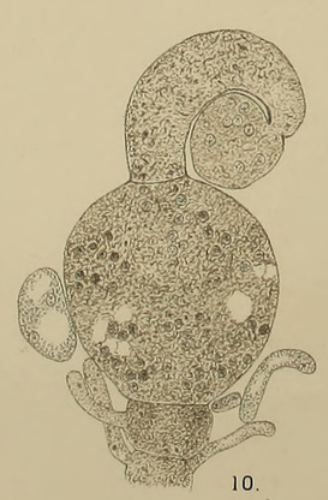

10.

9.
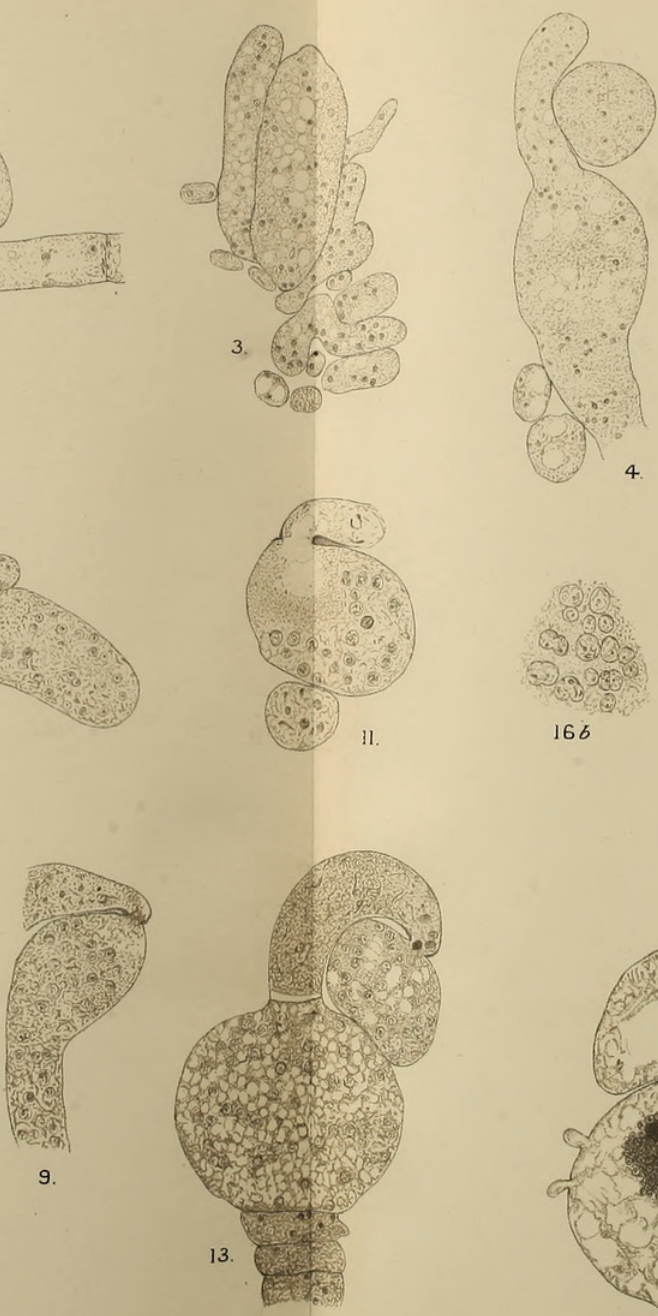

13.

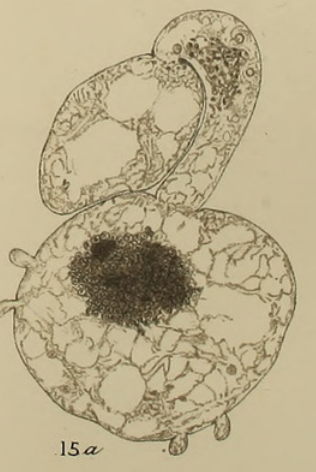

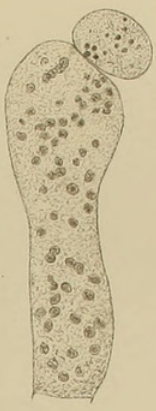

5
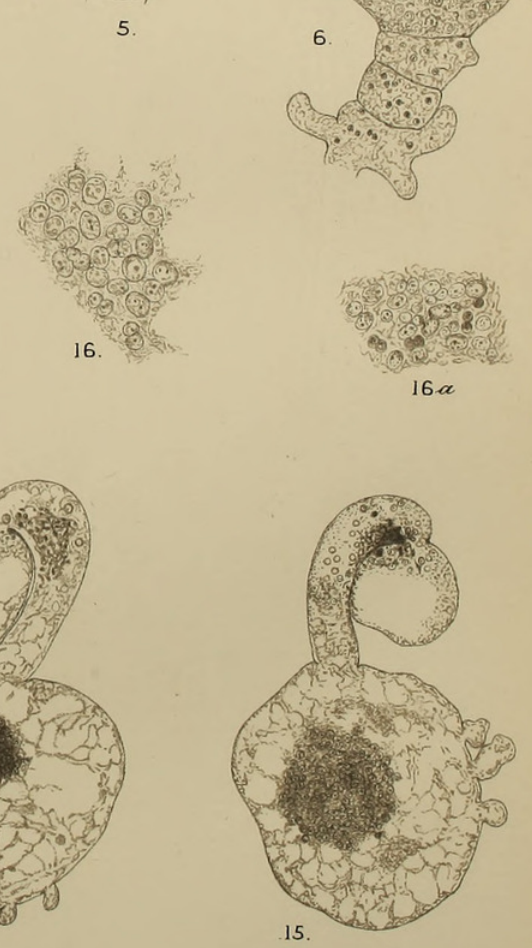

University Press, 0xford. 

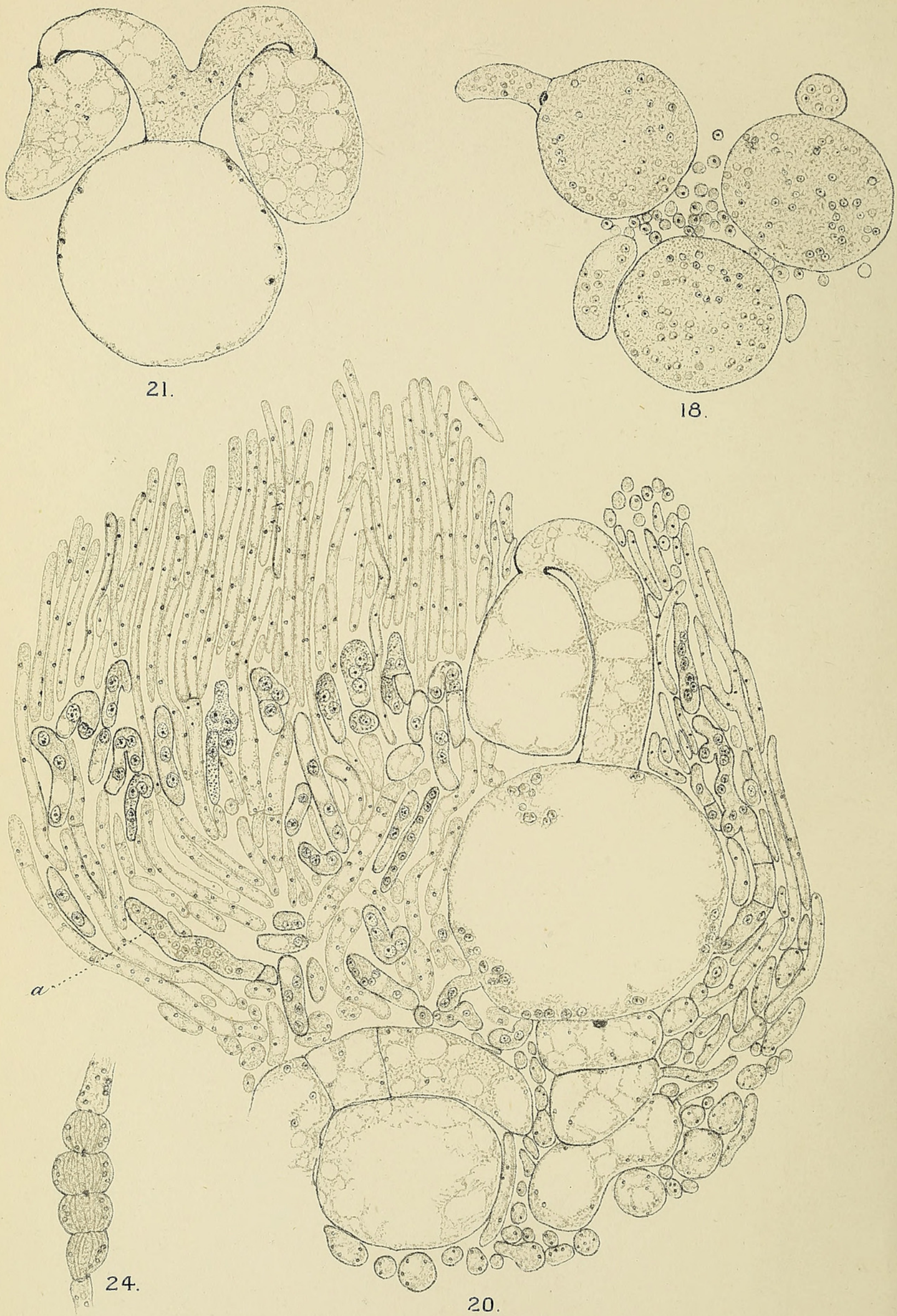


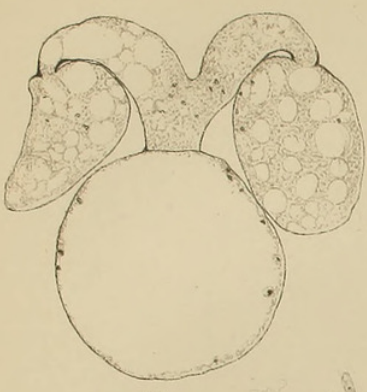

21

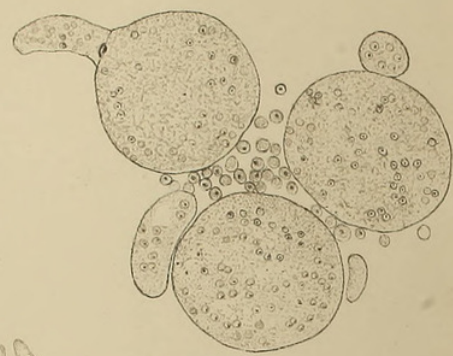

18.

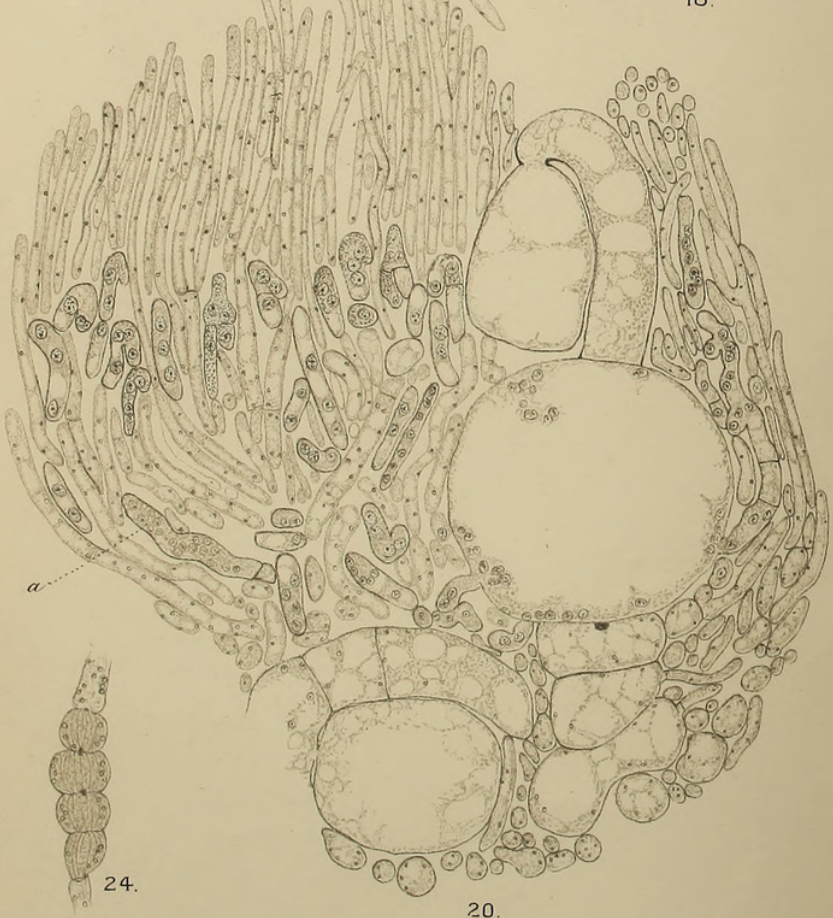

20.

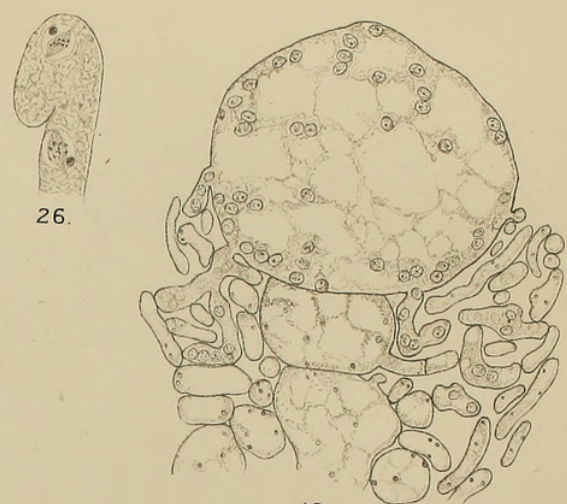

19
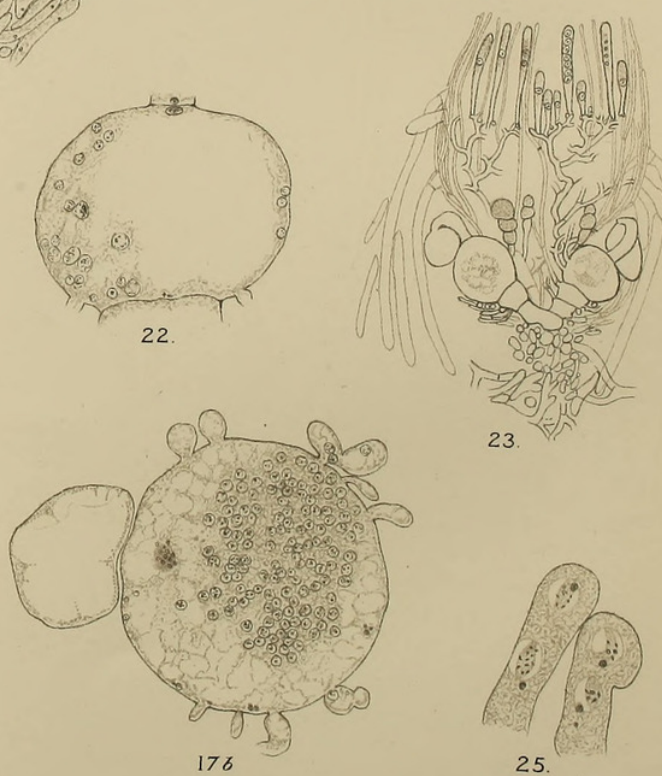

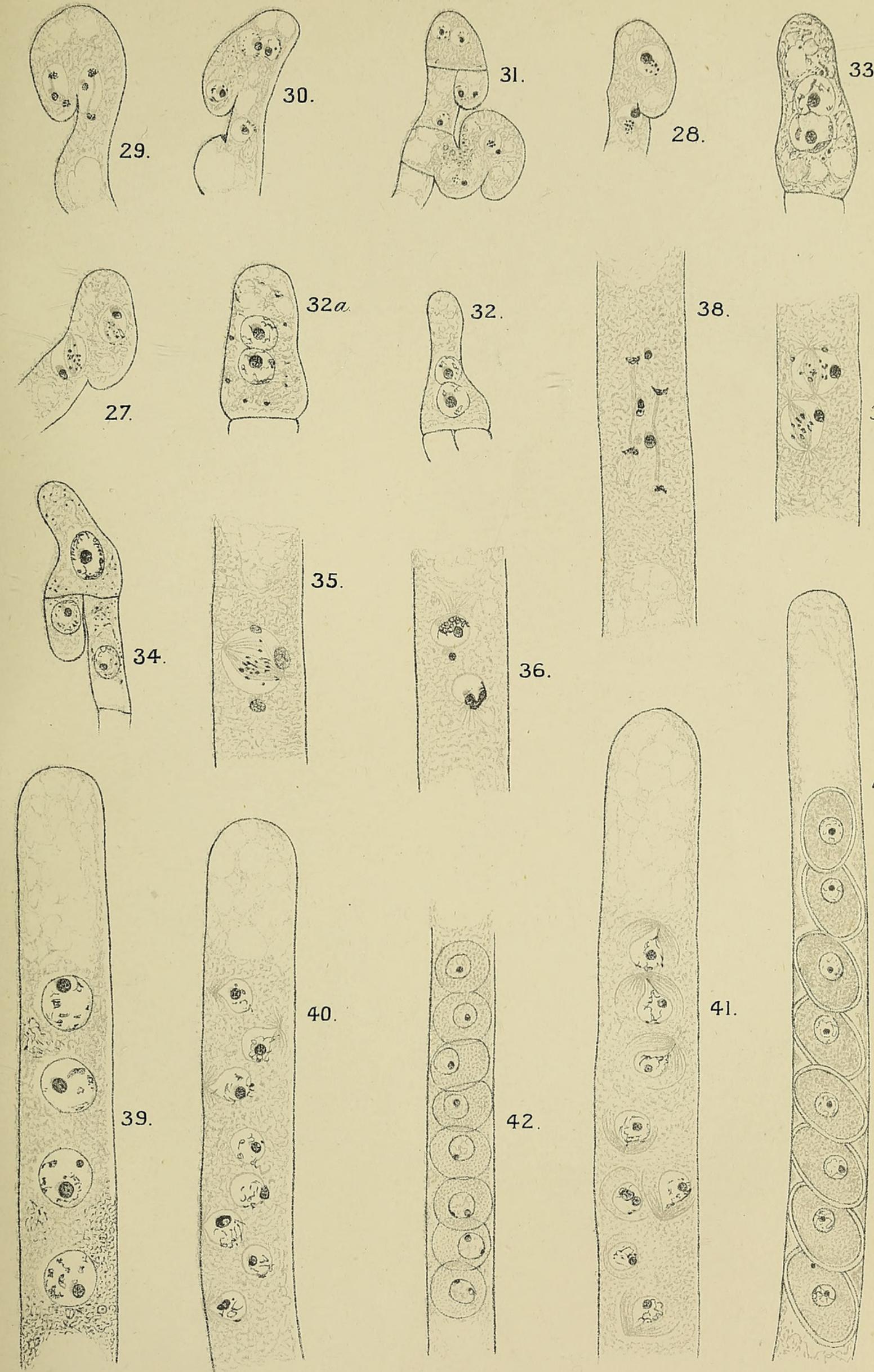

36.

8.
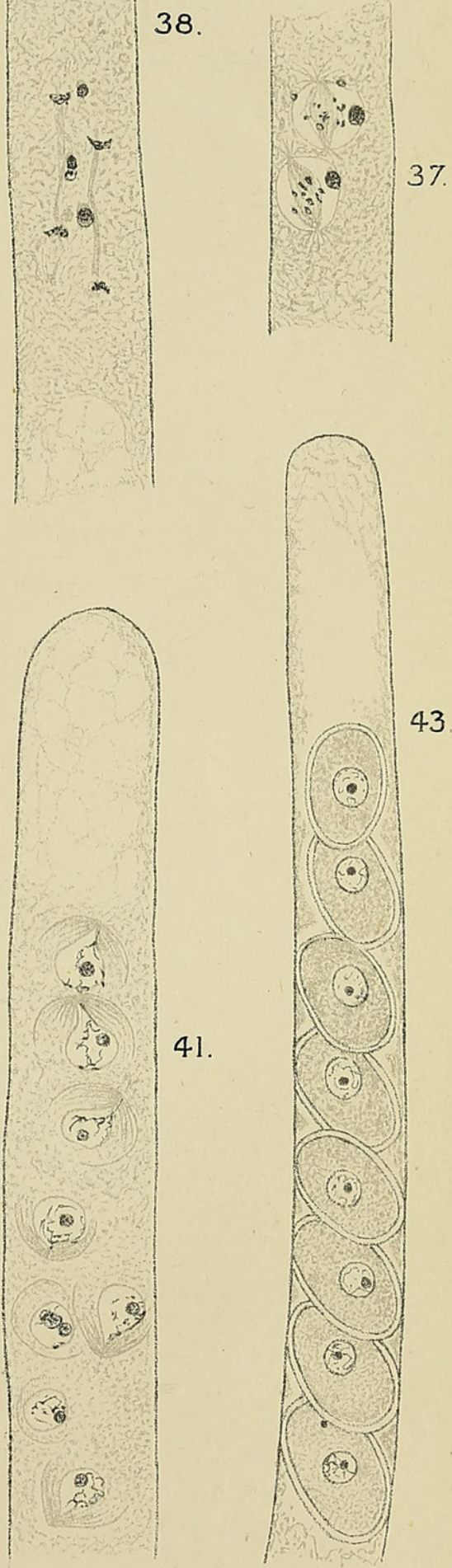

R.A.H., Del
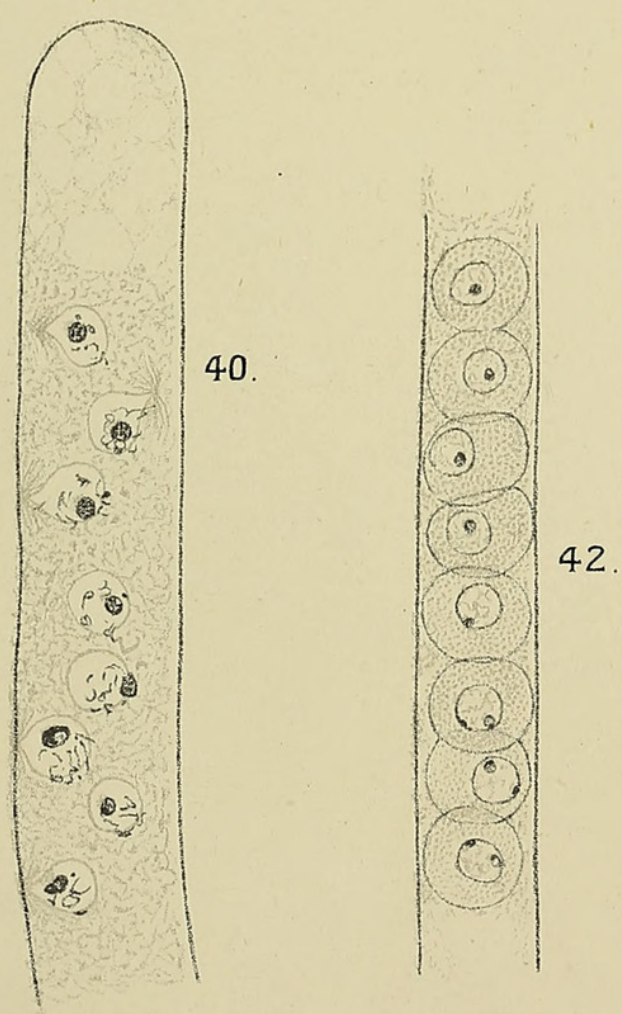

University Press, Oxford. HARPER - ON PYRONEMA 


\section{$2 \mathrm{BHL}$ Biodiversity Heritage Library}

Harper, Robert Almer. 1900. "Sexual reproduction in Pyronema confluens and the morphology of the ascocarp." Annals of botany 14, 321-400. https://doi.org/10.1093/oxfordjournals.aob.a088785.

View This Item Online: https://www.biodiversitylibrary.org/item/238259

DOI: https://doi.org/10.1093/oxfordjournals.aob.a088785

Permalink: https://www.biodiversitylibrary.org/partpdf/318592

\section{Holding Institution}

Smithsonian Libraries

\section{Sponsored by}

Biodiversity Heritage Library

\section{Copyright \& Reuse}

Copyright Status: Not in copyright. The BHL knows of no copyright restrictions on this item.

This document was created from content at the Biodiversity Heritage Library, the world's largest open access digital library for biodiversity literature and archives. Visit BHL at https://www.biodiversitylibrary.org. 